\title{
New Possibilities for Geophysical Parameter Retrievals Opened by GCOM-W1 AMSR2
}

\author{
Zabolotskikh Elizaveta ${ }^{1}$, Mitnik Leonid M., Reul Nicolas ${ }^{2}$, Chapron Bertrand ${ }^{2}$ \\ ${ }^{1}$ Satellite Oceanography Laboratory (RSHU SOLab), Russian State Hydrometeorological University, \\ 195196 St. Petersburg, Russia \\ 2 Ifremer, France
}

\begin{abstract}
:
A new approach to retrieve sea surface wind speed (SWS) in tropical cyclones (TCs) from the Advanced Microwave Scanning Radiometer 2 (AMSR2) data is presented. Analysis of all six AMSR2 Cand X-band channel measurements over TCs is shown to efficiently help to separate the rain contribution. Corrected measurements at 6.9 and $10.65 \mathrm{GHz}$ are then used to retrieve the SWS. Spatial and temporal collocation of AMSR2 and tropical rain measurement mission (TRMM) microwave instrument (TMI) data is then further used to empirically relate TMI rain rate (RR) product to RR estimates from AMSR2 in hurricanes. SWS estimates are validated with measurements from the stepped frequency microwave radiometer (SFMR). As further tested, more than 100 North Atlantic and North Pacific TCs are analyzed for the 2012-2014 period. Despite few particular cases, most SWS fields are in a very good agreement with TC center data on maximum wind speeds, radii of storm, and hurricane winds. As also compared, very high consistency between AMSR2 and L-band SMOS wind speed estimates are obtained, especially for the super typhoon Haiyan, to prove the high potential of AMSR2 measurements in TCs.
\end{abstract}

\section{Introduction}

Today the data for ocean winds are provided by different marine, aircraft, and satellite platforms with different accuracies and limitations. Remotely sensed measurements from passive and active microwave instruments ensure global wind mapping capabilities. Advantages and limitations of such measurement techniques in severe weather are often discussed, especially to improve knowledge of surface wind speeds (SWS) in hurricanes and typhoons [1]-[4]. As reported, active microwave copolarized backscatter signals of currently operating instruments (e.g., C-band Metop/ASCAT) saturate under hurricane force winds [5] and is 
heavily affected in the presence of high rain rates, ensuring an increasing role of microwave radiometry. More recently the potential of the cross polarized radar signal to sense hurricane winds was however demonstrated [6]-[8]. The study [9] describes the improvements in the QuikSCAT hurricane winds that might be reached by accounting for the rain attenuation and scattering. Yet, the implementation of this method requires simultaneous rain rate data. As already long been established [10]-[12], whitecaps, streaks and various associated foam structures at the ocean surface significantly contribute to increase the microwave emissivity of the sea surface. This emissivity increase is observable even when a very small portion of the sea surface is covered by foam formations. Contrarily to scatterometer signal, the radiometric signal does not saturate at high winds providing the potential for foam property and surface wind speed retrievals using passive microwave observations [1], [10], [13], [14]. Moreover, the sensitivity of microwave brightness temperature tends even to increase for the winds above $15 \mathrm{~m} / \mathrm{s}$ [15]-[17].

Until the launch of the Soil Moisture and Ocean Salinity (SMOS) satellite in 2009, most orbiting microwave radiometers operated at frequencies higher or equal to C-band. Measurements from Special Sensor Microwave Imager (SSM/I), Special Sensor Microwave Imager and Sounder (SSMIS), Tropical Rain Measurement Mission (TRMM) Microwave Instrument (TMI), Advanced Microwave Scanning Radiometer (AMSR), AMSR-E and WindSat are used to retrieve atmospheric and oceanic parameters such as cloud liquid water, water vapor, wind speed, rain rate, and sea surface temperature. AMSR-E onboard Aqua satellite stopped working in October 2011 but AMSR2 onboard GCOM-W1 satellite, launched in may 2012, ensures continuity. At C- and higher frequency bands, at which these instruments are operating, atmospheric absorption, emission and scattering associated with high cloud liquid and ice water content and intense precipitations in tropical cyclones (TCs) have large impacts on the brightness temperatures. Microwave radiation at L-band is almost transparent to atmosphere [18] and with negligible impacts of precipitation and water clouds with respect those reported at higher frequency bands. L-band ocean emissivity is less sensitive (by about a factor 3) to sea surface state changes at high winds than at the higher C- and X-band microwave 
frequencies but as demonstrated in [13], the data from SMOS mission operating at L-band can be successfully used to retrieve ocean surface winds under rain in severe weather conditions.

Though satellite passive microwave techniques to retrieve oceanic and atmospheric parameters under nonrain conditions are well established [19], [20], measurements of the oceanic parameters under rain conditions are still a challenge [21]. In [22] an approach is suggested to estimate surface winds from the WindSat data using the calculation of the atmospheric transmittance. Yet, this approach was shown in [22] to be unsuccessful under TC high wind and rain conditions. The physics of the sea surface remote sensing is not understood completely under severe weather conditions including high winds and precipitation. Intensive rains both shield the ocean surface and change the ocean surface emissivity in a complicated manner. Rain affects on the sea surface roughness through the downdrafts, altering surface wave spectrum, and impinging on the surface producing splashes and generating turbulence in the upper water layer [23]. Moreover, recent studies indicate the strong correlation between high rain rates and high wind speeds in the areas encircling TC eyes [24]. This complicated air-sea interaction is hard to be theoretically modeled especially for such extreme events as TCs combining the strongest precipitation and hurricane-force winds leading to appearance of whitecaps, foam streaks and spray layer [13], [25].

The microphysical processes describing the growth, decay, and fallout of precipitation particles within TCs are very complicated, different in eyewall clouds and in rainbands, and may fast change in time during TC development [26]. Beside liquid water drops, various forms of frozen hydrometeors may compose the microphysical structure of TC clouds. For example in [27], the microphysical package, used in the TC numerical model, features 12 hydrometeor habits, including cloud droplets, rain, cloud ice and different forms of graupel, snow and hail. Some of these habits due to their large sizes affect the radiances at C- and X-band microwave frequencies. Thus, though many algorithms have been developed to measure ocean surface wind speeds with an accuracy of about or less than $1 \mathrm{~m} / \mathrm{s}$ for non-rain conditions [28]-[30], most of them break down completely if even only light rain is present. 
In principle, sea surface wind speed retrievals in hurricanes under rain are possible if one can assume that the brightness temperatures are far from saturation. Numerical modeling shows that this is true for rain rates up to 20-30 mm/h for C and X-band channels [31]. Non saturated brightness indicates that the radiometer can sense the ocean surface changes even under rain and the measured signal can be used to derive its properties. The practical implementation of $\mathrm{C}$ and X-band channel measurement usage for SWS retrievals under rain from WindSat data is presented in [21]. In that study an empirical SWS algorithm, exploring C and X-band channel measurement data, is developed using WindSat data, collocated with $\mathrm{H}^{*}$ Wind fields considered as quasi ground-truth data [32]. The major problem concerns the separation of the ocean radiation from that of precipitating atmosphere. Such a separation is possible when the brightness temperature signals at different frequencies are available, whose spectral signatures make it possible to find the channel combinations that are sensitive to wind speed, and significantly less sensitive to rain. Such a technique has been explored successfully for wind speed retrieval from the Stepped-Frequency Microwave Radiometer (SFMR), which operates at six close C-band frequencies from $\sim 4$ to $7 \mathrm{GHz}$ [16], [33] The data from the NOAA SFMR are considered to be among the most accurate marine wind observations for hurricane winds [34]. This becomes a much more difficult task when considering orbiting radiometers such as AMSR-E, or WindSat, which probe the Earth at several frequencies but in clearly separated bands, with each channel having very distinct geophysical dependencies on various atmospheric and oceanic parameters.

The new Japan passive microwave instrument AMSR2, launched in May of 2012, has four C-band channels at the frequencies of 6.925 and $7.3 \mathrm{GHz}$ [35]. This instrument features improved calibration with respect AMSR-E and a higher spatial resolution due to larger antenna diameter. The addition of two new Cband channels was initially intended for the radio frequency interference (RFI) pixel identification. But they might be also explored the same way as in SFMR, since the signal at close frequencies has similar sensitivity to the sea wind speed but differs in sensitivity to rain by about $12 \%$. In this study this new possibility to retrieve sea surface wind speed under rain in hurricanes is studied through the analysis of AMSR2 brightness 
temperature $\left(T_{B}\right)$ fields over TCs, using some assumptions concerning $T_{B}$ dependencies on atmospheric and oceanic parameters.

Many investigators have been studying the sensitivity of brightness temperatures to cloud and rain microphysical properties for the application to passive microwave remote sensing from satellite [36]-[39]. These studies rarely concern C- or X- band frequency measurements since these bands are typically used for the ocean parameter retrievals, the atmosphere being significantly more transparent for the radiation at these lower microwave frequencies.

Simulation of the microwave brightness temperatures over the oceans as functions of frequency [31], [39], [40] shows that in general, the brightness temperatures increase towards a maximum and then drop off due to scattering as rainfall rate (RR) increases further. The range of RRs for $T_{B}$ increase (emission/absorption range) depends on the microwave frequency and the hydrometeor size distribution. The larger the frequency, or the percent of large particles at the same rain rate, the more important role the atmospheric scattering plays. $T_{B}$ at lower frequencies including $\mathrm{C}$ - and $\mathrm{X}$-bands tends to increase through much of the rainfall range, thus, making them suitable in modeling for emission type schemes. $T_{B}$ at higher frequencies saturates quickly and decreases for much of the rainfall range [31], [41].

In tropical cyclones, rain intensity, the presence of large drops in the raindrop-size distribution, and hail dominantly contribute to the brightness temperature signal measured at X-band and even at C-band. These contributions from rain can mask the ocean surface signature through either saturation or even cooling (due to scattering) of the brightness temperature.

The approach to separate rain-induced $T_{B}$ from non-rain atmosphere-ocean system $T_{B}$, presented in this paper, is based on the analysis of AMSR2 measured $T_{B}$ fields over TCs. The proposed technique relates AMSR2 brightness temperature differences at $\mathrm{C}$ - and $\mathrm{X}$-band channels at vertical polarization to rain microwave radiance and is described in section II. After subtraction of the rain radiance from the total $T_{B} S$ the 
residual $T_{B}$ are supposed to be appropriate as the inputs for the non-rain SWS AMSR2 retrieval algorithm developed earlier [42].

SWS have been estimated for 110 Atlantic and Pacific TCs intercepted by AMSR2 swath over the period 2012-2014 and further compared to the data from the Japan Meteorological Agency, archived by the Joint Typhoon Warning Center (JTWC), and the NOAA's Hurricane Research Division (HRD), processed by the Atlantic Oceanographic \& Meteorological Laboratory (AOML). In section III, SWS and RR retrieved fields are presented for some of TC cases in comparison with other available satellite products. In section IV, AMSR2 retrieved wind speeds are further compared with those retrieved from SMOS [13] for some specific TC cases, including the super typhoon Haiyan that devastated Philippines in 2013. Further validation of the approach is done by means of the comparison of AMSR2 winds with SFMR data for two flights over TCs.

\section{MethodolOgy}

\section{A. AMSR2 SWS rain free retrieval algorithm}

An AMSR2 rain-free sea surface wind speed retrieval algorithm was developed and extensively validated earlier [42]. This is a physical algorithm based on the numerical simulation of the microwave brightness temperature of the atmosphere-ocean system under non-precipitating conditions. In [42] two separate AMSR2 SWS algorithms are considered. The first algorithm uses AMSR2 six brightness temperatures $T_{B}$ at the AMSR2 frequency channels 18.7, 23.8 and $36.5 \mathrm{GHz}$, horizontal and vertical polarization (higher frequency algorithm). The second one (lower frequency (LF) algorithm) uses four brightness temperatures at the lower frequency channels: 6.9 and 10.65, horizontal and vertical polarization. Both algorithms use simulated microwave radiances and Neural Networks (NNs) approach to create inversion operators for the algorithm derivation. The simulation is based on the version of the geophysical model that includes empirical ocean emissivity and atmospheric absorption models taking into account the emission and absorption of oxygen, water vapor and cloud liquid water [43]. For the construction of the data set of simulated $T_{B}$ and 
wind speeds, computer simulations of the brightness temperatures were carried out for the input data set of more than 2500 collocated atmospheric and oceanic in-situ data, representing the global spectrum of the atmospheric and oceanic conditions. These simulations were fulfilled for the frequencies, polarization, sensitivity, and sensing geometry of the AMSR2 instrument. NNs were trained for SWS retrievals after adding a radiometric noise with $0.5 \mathrm{~K}$ equivalent temperature to the simulated $T_{B}$ values. Before application to actual measurement data special adjustment of simulated brightness temperature values to measured ones were done as described in [43].

The algorithms are based on a radiative transfer model valid for non-precipitating conditions and therefore involve specifically developed atmospheric filter to mask rain pixels [44]. Both higher frequency and lower frequency algorithms were extensively validated against in-situ measurement of wind speed data from oil platform stations in the North Sea and Norwegian Sea, including high wind events.

This study explores the LF rain-free algorithm since here an attempt is undertaken to retrieve SWS under rainy conditions. The approach successively consists in i) estimation of the rain contribution to the total microwave emission, ii) correction of rain effects on the latter, and (iii) application of the rain free algorithm to the residual $T_{B}$. We used rather simplifying assumptions (detailed in the next section) not valid for frequencies higher X-band.

\section{B. Rain TB empirical estimation.}

To derive empirical estimation of rain $T_{B}$ over TCs, the AMSR2 $T_{B}$ fields have been analyzed for 18 cases of typhoons. AMSR2 Level 1B swath brightness temperature data have been supplied by the GCOM-W1 Data Providing service, Japan Aerospace Exploration Agency. The spatial resolution of $T_{B}$ varies depending on the channel frequency but the grid spacing is the same - $10 \mathrm{~km} \times 10 \mathrm{~km}$ - for all the channels except 2 channels at $89 \mathrm{GHz}$ for which it is $5 \mathrm{~km} \times 5 \mathrm{~km}$. Thus, AMSR2 Level $1 \mathrm{~B} T_{B}$ data at C-and X-band channels are provided on the same irregular grid [45]. The actual resolutions of AMSR2 C- and X-band channels are - 
$35 \mathrm{~km} \times 62 \mathrm{~km}$ for $6.9 \mathrm{GHz}, 35 \mathrm{~km} \times 62 \mathrm{~km}$ for $7.3 \mathrm{GHz}$, and $34 \mathrm{~km} \times 58 \mathrm{~km}$ for $10.65 \mathrm{GHz}$ channels. In fact, due to the horn location differences the brightness temperatures of different frequencies, even stored in the same pixel, are measured in different areas. In case of large atmospheric or oceanic inhomogeneity the usage of these brightness temperatures as inputs in parameter retrieval algorithms decreases the retrieval accuracy. To compensate for the different channel resolution AMSR2 L1R product of resampled to a common resolution brightness temperatures is now available. Its usage will reduce the retrieval errors associated with different spatial resolution of the channels. From the Digital Typhoon database (http://agora.ex.nii.ac.jp/digital-typhoon/), we selected only those typhoons for which the radii of the hurricane-force winds were reported (by JTWC) to be axis-symmetric and where we found non-precipitating along with rainy areas observed at the same distance from the typhoon center. These criteria are necessary for the attempt to isolate the rain portion of $\mathrm{C}$ - and $\mathrm{X}$-band measured brightness temperature over the ocean from the other portion including the ocean radiation and the radiation of the atmosphere without rain. To separate the two contributions, we considered the microwave radiation of the atmosphere-ocean system taken over the footprints located at equal distance from the typhoon centers. Accurate typhoon center locations have been determined using MODIS high resolution data with only few minute time differences with AMSR2 acquisitions. The MODIS Level 1B Calibrated Radiances used in this study were acquired as part of the NASA's Earth-Sun System Division and archived and distributed by the MODIS Adaptive Processing System (MODAPS). This data set contains several products of different resolution. MODIS Level 1B 250M Earth View data product for MODIS bands 1 and 2 at 250 meter resolution has been used [46]. The coordinates of the cloudless center of the cyclone were determined from the MODIS images. Then they were shifted according to the differences in time between AMSR2 and MODIS measurements and the cyclone movement velocities as it was done in [47]. The general assumption is that for TCs with symmetric radii of hurricane force winds, (JTWC information) the variation of the microwave radiance due to wind changes at the same 
distance from the center is negligible with respect to that of induced by rain rate variations. Two examples of such cases are shown in Fig. 1 and Fig. 2.

Fig. 1 shows the brightness temperature fields measured by AMSR2 at $10.65 \mathrm{GHz}$, vertical polarization over the typhoons Haiyan (a) and Danas (b). Black circles are plotted at a radius of about $200 \mathrm{~km}$ for Haiyan and $110 \mathrm{~km}$ for Danas. In [48] the convective and rainfall properties of tropical cyclones are summarized based on the 11 year analysis of high resolution TRMM Precipitation Radar data. Common precipitation features are found for tropical cyclones. Most of the tropical cyclones at different intensity stages exhibit an inner core (IC) region, including either complete or incomplete eye walls, and for storms without an eye the near-center is still an intense convection zone. The inner rain band (IB) region includes banded or bloblike precipitation immediately outside of the IC boundary. It usually extends from the IC boundary outward about $100 \mathrm{~km}$, and is bounded on the outside by a rain free region adjacent to the outer rain band. According to this classification, most part of the circles in Fig. 1 goes over the inner rain band (IB) region whereas some part (at least, the arcs A and B, marked with thick dark green line) covers typical for IB rain free region adjacent to the outer rain band. Fig. 2 shows $T_{B}$ fields for the same typhoons measured by AMSR2 at 89 GHz, vertical polarization. $T_{B}$ values at this high frequency channel are equal approximately $280 \mathrm{~K}$ for the arcs $\mathrm{A}$ and B. These values, along with the whole $T_{B}$ field around, indicate the absence of ice or rain scattering (contrarily to the eyewall and spiral rainband areas which exhibit much lower Tb values), and even $T_{B}$ saturation at $89 \mathrm{GHz}$ is not reached for these areas.

We assumed absence of rain for the arcs A and B (and similarly for selected arcs chosen for a total of 18 typhoon cases that were analyzed), so that the brightness temperatures measured over these areas at 6.9 $\mathrm{GHz}, 7.3 \mathrm{GHz}, 10.65 \mathrm{GHz}$, vertical and horizontal polarizations, are the $T_{B} S$ of the ocean and atmosphere without rain. These $T_{B} S$ will be denoted further as $T_{B 6}{ }^{V} 0, T_{B 6}{ }_{0}^{H}, T_{B 7}{ }^{V}, T_{B 7}{ }_{0}^{H}, T_{B 10}{ }_{0}, T_{B 10}{ }_{0}$ correspondingly. Along the cloudless arcs A and B the range of brightness temperature changes is very small, within $0.5 \mathrm{~K}$ for C-band $T_{B}$ and within $1.5 \mathrm{~K}$ for $\mathrm{X}$-band $T_{B} S$. The next step is then to find the rain contribution to $T_{B} S$ for 
those channels which are used in the sea surface wind speed AMSR2 LF retrieval algorithm (these constituents will be denoted as $T_{B 6}{ }_{R}^{V}, T_{B 6}{ }_{R}^{H}, T_{B 10}{ }_{R}, T_{B 10}{ }_{R}$ ) and express them in terms of some measured values so that then one could subtract $T_{B 6}{ }_{R}, T_{B 6}{ }_{R}, T_{B 10}{ }_{R}, T_{B 10}{ }_{R}^{H}$ from the total measured radiances and apply the algorithm as if there were no rain.

Analyzing brightness temperatures from the measurement pixels along the circle of equal distance from the typhoon center we make several assumptions. First, we suppose that for defined circles of equal distance from the typhoon center cloud liquid water content and atmospheric water vapor content variations influencing $T_{B}$ in C- and X-bands are negligible comparatively to rain drop parameter variations (drop size, form and their distribution in the vertical profile and over the footprint). Strictly speaking this is not correct. But the influence of total atmospheric water vapor content (TWV) and cloud liquid water content (CLW) on $T_{B}$ in C- and X-bands is considerably lower than on $T_{B}$ at higher frequency channels. Numerical simulations show that the increase in TWV of as large as $10 \mathrm{~kg} / \mathrm{m}^{2}$ will lead to AMSR2 $T_{B}$ increase of $\sim 0.4 \mathrm{~K}$ in C-band and $\sim 1 \mathrm{~K}$ in X-band $T_{B}$ measurements at vertical polarization. The increase in CLW of $0.5 \mathrm{~kg} / \mathrm{m}^{2}$ will lead to $T_{B}$ increase of $\sim 2 \mathrm{~K}$ in $\mathrm{C}$-band and $\sim 6 \mathrm{~K}$ in $\mathrm{X}$-band values also at vertical polarization. This is much less than the expected signature from precipitation parameter variations [23].

The second assumption concerns the wind speed variations along the circles and their influence on $T_{B}$. These variations cannot be priori considered negligible. The surface wind field can be asymmetric, and the wind speed differences at the radius of maximum winds (RMW) can be as large as $3-10 \mathrm{~m} / \mathrm{s}$. Out of the hurricane-force radii the surface wind asymmetry is about 30\% lower than at RMW [50]. But the wind dependency in C- and X-bands is very similar. So to some extension the differences in measurements $\Delta T_{B}{ }^{V}{ }_{7,6}=T_{B 7}{ }^{V}-T_{B 6}{ }^{V}$ and $\Delta T_{B}{ }^{V} 10,7=T_{B 10}{ }^{V}-T_{B 7}{ }^{V}$, estimated along the circle of equal distance from the center of the typhoon, can be considered independent of the sea state and dominantly functions of the rain 
properties. The differences in measurements at horizontally polarized channels are not considered here due to their larger dependency on wind speed changes than for vertically polarized channels.

To summarize, we express the brightness temperature $T_{B}$ over the rainy part of the circles as a sum of two components: brightness temperature of the non-rain atmosphere and ocean $T_{B 0}$ and brightness temperature of rain $T_{B R}$. To find $T_{B R}$, we assume constant value for $T_{B 0}$ along a circle. To estimate the errors introduced by the last approximation we performed numerical calculations of the brightness temperatures of the atmosphere - ocean system using the geophysical model developed in [43], complemented by liquid water content absorption and rain rate attenuation parameterized in accordance with [51].

In its simplified form, the radiative transfer equation (RTE) for the brightness temperature of the atmosphere - ocean system can be written as:

$$
\cos \theta \cdot \frac{d T_{B}}{d z}=-\alpha(z) T_{B}+\alpha(z) T(z)
$$

This “absorption only" form of RTE, where the absorption coefficient $\alpha_{a b s o r p t i o n}$ is replaced by the total attenuation coefficient $\alpha$, accounts accurately for the negative effect of scattering and approximately for its positive effect due to forward scattering [52]. As well, it does not account for the polarization effect of scattering which increases with rain rate and microwave frequency. The solution of the equation (1) is $T_{B}$, which can be presented as a sum of several contributions:

$$
T_{B}=T_{B a}^{u p}+T_{B a}^{\text {down }}+T_{B S}+T_{c}
$$

where $T_{B a}^{u p}$ is the upwelling atmospheric radiation, $T_{B a}^{\text {down }}$ is the downwelling atmospheric radiation, reflected by the sea surface and attenuated further in the atmosphere, $T_{B S}$ is the sea emitted radiation, also attenuated in the atmosphere, and $T_{c}$ is the cosmic radiation. $T_{B a}^{u p}$ and $T_{B a}^{\text {down }}$ can be presented as: 


$$
\begin{gathered}
T_{B a}^{\text {up }}=\frac{1}{\cos \theta} \int_{0}^{\infty} T(h) \alpha(h) \exp \left(-\frac{1}{\cos \theta} \int_{h}^{\infty} \alpha\left(h^{\prime}\right) d h^{\prime}\right) d h \\
\left.T_{B a}^{\text {down }}=(1-E) \cdot \exp (-\tau) \cdot\left(\frac{1}{\cos \theta} \int_{0}^{\infty} T(h) \alpha(h) \exp \left(-\frac{1}{\cos \theta} \int_{0}^{h} \alpha\left(h^{\prime}\right) d h^{\prime}\right) d h\right)\right)
\end{gathered}
$$

where $T$ is the atmospheric temperature, $E$ is the sea surface emission coefficient, strongly dependant on the sea surface wind speed, $\tau$ is the atmospheric optical thickness defined as:

$$
\tau=\frac{1}{\cos \theta} \int_{0}^{\infty} \alpha(h) d h
$$

The sea radiation depends on its physical temperature and emission coefficient:

$$
\begin{gathered}
T_{B S}=T_{S} \cdot E \cdot \exp (-\tau) \\
T_{C}=2.7 \cdot \exp (-2 \tau) \cdot(1-E)
\end{gathered}
$$

For the simplified isothermal atmosphere with $T(h)=T_{\mathrm{s}}-\Delta T=T$, where $\Delta T=10-15^{\circ} \mathrm{K}$ is the correction for nonisothermity, the upwelling and downwelling atmospheric radiations are equal [53] and can be presented as a sum of $T_{a}$ and $T_{R}$, where:

$$
\begin{aligned}
& T_{B a}^{\text {up }}=\frac{1}{\cos \theta} \int_{0}^{\infty} T(h) \alpha(h) \exp \left(-\frac{1}{\cos \theta} \int_{h}^{\infty} \alpha\left(h^{\prime}\right) d h^{\prime}\right) d h=T \cdot\left\{1-\exp \left(\tau_{0}+\tau\right)\right\} \approx T_{a}+T_{R} \\
& \left.T_{B a}^{\text {down }}=(1-E) \cdot \exp (-\tau) \cdot\left(\frac{1}{\cos \theta} \int_{0}^{\infty} T(h) \alpha(h) \exp \left(-\frac{1}{\cos \theta} \int_{0}^{h} \alpha\left(h^{\prime}\right) d h^{\prime}\right) d h\right)\right)= \\
& \quad=(1-E) \cdot \exp (-\tau) \cdot T \cdot\left\{1-\exp \left(\tau_{0}+\tau\right)\right\} \approx(1-E) \cdot \exp (-\tau) \cdot\left(T_{a}+T_{R}\right)
\end{aligned}
$$

where $T_{\mathrm{a}}=T \tau_{\mathrm{o}}, T_{\mathrm{R}}=T \tau_{\mathrm{R}}, \alpha_{R}$ - rain attenuation coefficient, $\alpha_{0}$ - atmospheric absorption coefficient. 
Actually, $\alpha_{R}$ represents a liquid water attenuation coefficient consisting of absorption by cloud and small rain droplets and of attenuation by large rain drops. In such a case $\alpha_{0}$ is an absorption coefficient of clear atmosphere (molecular oxygen and water vapor).

Neglecting $T_{\mathrm{c}}$ due to its smallness ( $<2 \mathrm{~K}$ ) we can now rewrite (2) as

$$
T_{B}=\left(T_{a}+T_{R}\right)+\left(T_{a}+T_{R}\right) \cdot(1-E) \cdot \exp \left(-\left(\tau_{R}+\tau_{0}\right)\right)+T_{S} \cdot E \cdot \exp \left(-\left(\tau_{R}+\tau_{0}\right)\right)
$$

So, the brightness temperature of the system can be written as a sum of two components:

$$
T_{B}=T_{B R}+T_{B A O S}
$$

where $T_{B A O S}$ is:

$$
T_{\text {BAOS }}=T_{a}+T_{a} \cdot(1-E) \cdot \exp (-\tau)+T_{S} \cdot E \cdot \exp (-\tau)
$$

and $T_{B R}$ is:

$$
T_{B R}=T_{R}+T_{R} \cdot(1-E) \cdot \exp (-\tau)
$$

- the brightness temperature of the rain constituent of the atmosphere, which due to its downwelling reflected part is also a function of the sea state.

The brightness temperature of the system over the arcs $\mathrm{A}$ and $\mathrm{B} T_{B 0}$ is:

$$
T_{B 0}=T_{a 0}+T_{a 0} \cdot(1-E) \cdot \exp \left(-\tau_{0}\right)+T_{S} \cdot E \cdot \exp \left(-\tau_{0}\right)
$$

Assuming a constant value for $T_{B 0}$ along the circle, i.e., assuming $T_{B A O S}=T_{B O}$, is equivalent to replacing actual $T_{a}$ by $T_{a 0}$ and actual $\exp \left(-\left(\tau_{0}+\tau_{R}\right)\right)$ by $\exp \left(-\tau_{0}\right)$. Making such assumption translates into an

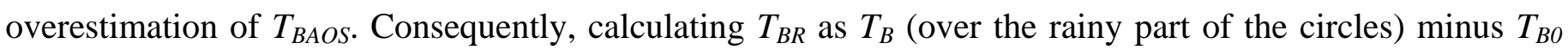
(over the $\operatorname{arcs} \mathrm{A}$ and $\mathrm{B}$ ), we underestimate the actual value of the rain radiance. The larger the wind is the 
larger the underestimation errors are. Numerical calculations have been done to estimate these errors. Fig. 3 shows the differences between $T_{B O}$, calculated according to (14), and $T_{B A O S}$ with actual $T_{a}$ (calculated according to (8)) and reduced by a factor of $\exp \left(\tau_{R}\right)\left({ }^{T_{B a}^{\text {down }}}+T_{B S}\right)$, at SWS $=20 \mathrm{~m} / \mathrm{s}$, as functions of the rain rate $\mathrm{R}$ for 6.9 and $10.65 \mathrm{GHz}$, horizontal and vertical polarization. The calculations have been performed for a typical tropical atmosphere. The rain optical thickness has been calculated supposing constant rain rate up to $5 \mathrm{~km}$. The values of TWV and CLW equal to $70 \mathrm{~kg} / \mathrm{m}^{2}$ and $0.9 \mathrm{~kg} / \mathrm{m}^{2}$ respectively. Even such simplified calculation allows concluding that large rain radiance estimation errors result from the approximation of the constant attenuation along the circles. At the rain depth of $5 \mathrm{~km}$, rain rate of $10 \mathrm{~mm} / \mathrm{h}$ and sea surface wind speed of $20 \mathrm{~m} / \mathrm{s}$ the errors are as large as $5 \mathrm{~K}$ for $6.9 \mathrm{GHz}$, horizontal polarization, $12 \mathrm{~K}$ for $6.9 \mathrm{GHz}$, vertical polarization, $16 \mathrm{~K}$ for $10.65 \mathrm{GHz}$, horizontal polarization and $34 \mathrm{~K}$ for $10.65 \mathrm{GHz}$, vertical polarization. SWS increase leads to the increase of these errors. The polarization effect of precipitating hydrometeors can also magnify the errors for horizontally polarized radiation. Equation (10) also indicates that by trying to separate the rain radiance, we inevitably include in $T_{B R}$ the downwelling part depending on the sea state. This also generates errors which nevertheless decrease with higher wind speeds (higher values of $E$ ) and rain rates $\left(\tau_{R}\right)$. Fig. 4 shows the differences in the calculated values of the downwelling part of $T_{B R}$ at SWS $=0 \mathrm{~m} / \mathrm{s}$ and SWS $=40 \mathrm{~m} / \mathrm{s}$ as functions of the rain rate R at 6.9 and $10.65 \mathrm{GHz}$, horizontal and vertical polarization. At the rain rate of $10 \mathrm{~mm} / \mathrm{h}, 40 \mathrm{~m} / \mathrm{s}$ difference in the wind speed brings the errors of about $2-3 \mathrm{~K}$ at $6.9 \mathrm{GHz}, 5 \mathrm{~K}$ at $10.65 \mathrm{GHz}$, vertical polarization and of about $12 \mathrm{~K}$ at $10.65 \mathrm{GHz}$, horizontal polarization. Thus, neglecting wind dependency of $T_{B R}$ leads to much smaller errors than neglecting rain attenuation.

Having in mind all the sources of errors due to formulated above assumptions, we can write for the brightness temperature of rain: 


$$
\begin{aligned}
& T_{B 6}{ }^{V}=T_{B 6}{ }^{V}-T_{B 6}{ }^{V} 0 \\
& T_{B 6}{ }^{H}{ }_{R}=T_{B 6}{ }^{H}-T_{B 6}{ }^{H}{ }_{0} \\
& T_{B 10}{ }_{R}=T_{B 10}{ }^{V}-T_{B 10}{ }^{V} \\
& T_{B 10}{ }^{H}{ }_{R}=T_{B 10}{ }^{H}-T_{B 10}{ }^{H}{ }_{0}
\end{aligned}
$$

where $T_{B 6}{ }_{0}^{V}, T_{B 6}{ }_{0}^{H}, T_{B 10}{ }_{0}, T_{B 10}^{H} \sigma$ are the $T_{B} S$ of the ocean and atmosphere without rain taken from the arcs A, B and the other quantities used in the study: $T_{B 6}{ }^{V}, T_{B 6}{ }^{H}, T_{B 10}{ }^{V}, T_{B 10}{ }^{H}$ - are the brightness temperatures measured over the remaining arcs of the circles.

After estimating $T_{B 6}{ }_{R}, T_{B 6}{ }_{R}, T_{B 10}{ }_{R}, T_{B 10}{ }_{R}$, we parameterized these radiances as functions of the differences in vertically polarized measurements between the two C-band channels of $\operatorname{AMSR2}\left(\Delta T_{B}{ }_{7,6}\right)$ and between the $\mathrm{C}$ and $\mathrm{X}$-band channels $\left(\Delta \mathrm{T}_{B}{ }^{V}{ }_{10,7}\right)$ :

$$
\begin{aligned}
& T_{B 6}{ }_{R}=a_{0}+a_{1} \cdot \Delta T_{B}{ }_{7,6}+a_{2} \cdot \Delta T_{B}{ }^{V} 10,7 \\
& T_{B 6}{ }^{H}{ }_{R}=b_{0}+b_{1} \cdot \Delta T_{B}{ }^{V}{ }_{7,6}+b_{2} \cdot \Delta T_{B}{ }_{10,7} \\
& T_{B 10}{ }^{V}=c_{0}+c_{1} \cdot \Delta T_{B}{ }_{7,6}+c_{2} \cdot \Delta T_{B}{ }^{V} 10,7 \\
& T_{B 10}{ }_{R}^{H}=d_{0}+d_{1} \cdot \Delta T_{B}{ }_{7,6}+d_{2} \cdot \Delta T_{B}{ }_{10,7}
\end{aligned}
$$

The derived coefficients $a_{i}, b_{i}, c_{i}, d_{i}$ and measured values of $\Delta T_{B}{ }^{V}$, 6 and $\Delta T_{B}{ }^{V} 10,7$ will be used for the calculation of the rain radiances for any pixels in all areas of the TCs.

After calculation of rain brightness temperatures $T_{B R}$ using the differences in measurements in C- and X-band channels at vertical polarization $\Delta T_{B}{ }^{V}$ 7,6 and $\Delta T_{B}{ }^{V} 10,7$ T $T_{B R}$ is subtracted from the total measured brightness temperatures. Finally, the non-rain SWS retrieval algorithm is applied to the residuals $T_{B}$, assuming the latter are the brightness temperatures of non-precipitating systems. 
Note that the assumptions we made cannot be valid for all type of conditions encountered in cyclones, particularly at very high rain rates. Moreover, the ocean - atmosphere systems under hurricane conditions are complex both in terms of precipitating cloud systems and the ocean state and their interdependencies. Intensive precipitation changes both the atmospheric radiative properties and the ocean surface emissivity. The last effect is very difficult to model accurately under hurricane-force winds due to extremely complicated nature of breaking waves and the various forms of foam and spray layers encountered at the ocean surface in extreme conditions [25]. Our derived empirical coefficients, relating rain brightness temperature to $\Delta T_{B}{ }^{V}$ 7,6 and $\Delta T_{B}{ }^{V}$ 10,7 might therefore not be valid for the whole range of atmospheric and oceanic states encountered in TCs.

To investigate the impact of the natural variability of these conditions on the robustness of our empirical approach, the sets of coefficients $a_{i}, b_{i}, c_{i}, d_{i}$ were derived separately for 18 typhoons cases. The derived coefficients proved to be very stable for the 18 different cases somehow suggesting the robustness of our parameterization under differing hurricane conditions. Nevertheless, for precipitating areas outside hurricanes with RR $>15 \mathrm{~mm} / \mathrm{h}$, we sometimes obtained unrealistically high SWS values (comparatively to Metop ASCAT SWS). Care should be therefore taken in the application of the approach for the general conditions and more studies are needed to define the limits of its applicability.

\section{Rain rate estimation.}

Since rain influence on $T_{B}$ at C-band is significantly lower than at X-band [49], the channels in X-band are more appropriate for rain parameter estimation. Rain integral parameter - rain rate (RR) - can be related to rain microwave brightness temperature $T_{B 10}{ }_{R}$ as derived in the previous section. To estimate the functional dependency $T_{B 10}{ }_{R}(\mathrm{RR})$, we used the RR data from the Tropical Rainfall Measuring Mission's (TRMM) Microwave Imager (TMI). TMI data are produced by Remote Sensing Systems and sponsored by the NASA Earth Science MEaSUREs DISCOVER Project. Data, their description and supporting software tools are available at www.remss.com. TMI is a multi - channel, dual polarized, conical scanning passive 
microwave radiometer designed to measure rain rates over a wide swath under the TRMM satellite. TMI operates on the TRMM satellite in a semi-equatorial orbit, measuring microwave radiation in a wide swath of $850 \mathrm{~km}$ and covering a global region from $40 \mathrm{~S}$ to $40 \mathrm{~N}$. TMI data are provided as daily gridded data on a regular grid with 0.25 degree resolution, separated into ascending and descending orbit segments. RSS rain rates are calculated using the algorithm described in [54]. For the collocation with TMI RR product $T_{B 10} V_{R}$ were gridded onto the same grid. TRMM semi-equatorial orbit ensures TMI to sample the surface at all times of day. Collocated in space and time measurements between TMI and AMSR2 can thus be obtained for any day [55]. However, small time difference between the two sensors is a key requirement for the collocation since the rain field in typhoons changes very fast [48].

One of the considered typhoons satisfies the conditions under which the rain field within the typhoon did not change significantly during the time between TMI and AMSR2 measurements. Fig. 5(a) illustrates the rain rate field for the typhoon Danas on 7 October 2013 imaged by TMI (product of Remote Sensing Systems) at 18:36 UTC (time of measurements over the typhoon center), whereas Fig. 5(b) shows the rain brightness temperature $T_{B 10}{ }_{R}$ at $10.65 \mathrm{GHz}$ vertical polarization, estimated from AMSR2 measurement data at $\sim$ 17:14 UTC, using $\Delta T_{B}{ }^{V}$ 7,6 and $\Delta T_{B}{ }^{V}$ 10,7. Red dots in Fig. 5(a) and Fig. 5(b) indicate the center of the typhoon at $\sim$ 17:14 UTC - time of the AMSR2 overpass. It can be seen that one hour and a half after AMSR2 overpass, the typhoon moved north and the rain field structure weakly evolved. We therefore considered it possible to match both fields after shifting AMSR2 measurements to the north accordingly (so that to superimpose the typhoon centers on both images) and gridding both TMI RR and AMSR2 $T_{B 10}{ }_{R}$ onto the same grid. The dependency of RR on $T_{B 10}{ }_{R}$ derived after such manipulations is shown in Fig. 6 . The empirical relationship, thus derived is:

$$
\mathrm{RR}=0.27 T_{B 10}{ }_{R}
$$


We further use that relationship to estimate rain rate from the differences in AMSR2 measurements $\Delta T_{B}{ }_{7,6}$ and $\Delta T_{B}{ }_{10,7}$. This RR retrieval method has been preliminary tested by comparing AMSR2 retrieved RR with TMI RR product for a dataset of spatially and temporally collocated observations collected during 2012-2014. AMSR2 Level 1B ascending and descending swath data for 2012-2014 have been first gridded at a resolution of 0.25 degree onto the same grid than the TMI RR products within $40 \mathrm{~S}$ to $40 \mathrm{~N}$. Only those pixels for which the time lag between AMSR2 and TMI data was less than 30 minutes were considered. The comparison (not shown here) indicates reasonable performance of the algorithm for RR exceeding $10 \mathrm{~mm} / \mathrm{h}$ with an rms difference between AMSR2 and TMI RR of $1.4 \mathrm{~mm} / \mathrm{h}$. For lower rain rates it increases to 2.8 $\mathrm{mm} / \mathrm{h}$, indicating that our RR estimation method is not appropriate for low rain rate estimation.

\section{SEA SURFACE WIND SPEED ALGORITHM APPLICATION FOR TROPICAL CYCLONE STUDY}

Our AMSR2 SWS retrieval algorithm has been applied for the reconstruction of the sea surface wind speed fields for 110 tropical cyclones intercepted over the North Atlantic and North Pacific basins for 20122014 years. Maximum sustained wind speeds (SWS max $_{\text {) }}$ and wind speed radii for the North Pacific and Atlantic basins have been compared to the best track data from the Joint Typhoon Warning Center (http://agora.ex.nii.ac.jp/digital-typhoon) and from NOAA HRD Atlantic Oceanographic \& Meteorological Laboratory (http://www.aoml.noaa.gov/hrd/data_sub/hurr.html), respectively. For a subset ensemble of the AMSR2 intercepts for 93 TCs including a large variety of TC development stages, we find a root mean square difference between the AMSR2 and data center estimated maximum sustained wind speeds of $4.3 \mathrm{~m} / \mathrm{s}$. For these cyclones the radii of the gale, storm and hurricane winds, when available, conform in average within $60 \mathrm{~km}$ (the actual spatial resolution of AMSR2 SWS). These intercepts are featured by comparatively low $(<15 \mathrm{~mm} / \mathrm{h})$ maximum RR values, which are estimated from the nearest in time TMI data. Here we would like to underline that the actual rain rates might be much higher. The spatial smoothing reduces high values of rain rates, occurring over small portions of a $\sim 50 \mathrm{~km}$ long satellite passive microwave radiometer 
footprint. The range of rain rates over which our algorithm is valid need to be investigated more in depth using higher resolution data (e.g. the data of Precipitation Radar (PR) on TRMM or the new data of the DualFrequency Precipitation Radar on the Global Precipitation Mission) [56], taking into account not only RR values but also their distribution over a footprint. This is going to be done in the future.

For the remaining intercepts of 17 TCs, AMSR2 SWS retrievals show significant discrepancies with the data from the TC centers. Eleven cases out of seventeen are characterized by high RR $>15 \mathrm{~mm} / \mathrm{h}$ while for the six others, TRMM PR rain rates are about 10-20 times higher than TRMM TMI rain rates.

Several examples of the application of our new approach for SWS estimation from AMSR2 data in severe weather of TCs are discussed hereafter. SWS and RR fields from other available satellite products are also shown for comparison. All Remote Sensing Systems products (WindSat, AMSR2) are produced by Remote Sensing Systems and sponsored by the NASA Earth Science MEaSUREs DISCOVER Project and the NASA AMSR-E Science Team. They are gridded onto the same grid $\left(0.25^{\circ} \times 0.25^{\circ}\right)$. The preliminary validation of our RR retrieval algorithm was based on TMI data alone as RSS AMSR2 data were only made available recently. For SWS field comparison we systematically use the RSS WindSat all-weather product [21].

Typhoon Danas, an extremely dangerous Category 4 strength tropical cyclone, according to the Joint Typhoon Warning Center reached its peak intensity on 7 October 2013 with maximum sustained winds of 115 knots $(55 \mathrm{~m} / \mathrm{s})$. AMSR2 maximum SWS is estimated to be $53 \mathrm{~m} / \mathrm{s}$ in excellent agreement with that of JTWC. Fig. 7(a) shows SWS field retrieved from AMSR2 data for the typhoon Danas on 7 October 2013 at about 17:15 UTC. In Fig. 7(b) the WindSat RSS SWS at about 21:36 UTC is shown for comparison. The maximum wind is close to that of AMSR2 SWS $(50 \mathrm{~m} / \mathrm{s})$.

White pixels in Fig. 7(a) correspond not only to the land contaminated pixels in coastal areas but also to RFI contaminated areas. SWS retrieval algorithm, described in this paper, is based on the usage of the brightness temperature differences at C- and X-band channels at vertical polarization. In case of RFI at 7.3 
$\mathrm{GHz}$ or $10.65 \mathrm{GHz}$ these differences appear without any precipitation. So, before the algorithm application it is necessary to exclude from the consideration RFI contaminated pixels. Low level RFI contamination is difficult to be identified over oceans [57]. The method to discriminate RFI contaminated pixels from rain is based on the analysis of the modeled $\mathrm{T}_{\mathrm{B}}$ values and their differences. Several threshold values for the channel measurement differences are derived from the results of the numerical modeling and used for RFI detection before SWS algorithm application.

One of the West Pacific typhoons of 2014 is shown in Fig. 8. The tropical cyclone Halong with a minimum pressure of $915 \mathrm{mB}$ was assigned a category 5 super typhoon on 3 August 2014 with maximum winds of $53 \mathrm{~m} / \mathrm{s}$. On 4 August Halong underwent an eyewall replacement cycle and weakened to a category 4 typhoon. At 6:00 UTC maximum winds were reported by JTWC to be about $45 \mathrm{~m} / \mathrm{s}$. Fig. 8(a) shows AMSR2 SWS at about 4:36 UTC retrieved with our algorithm. Estimated maximum winds are about $47 \mathrm{~m} / \mathrm{s}$. Fig. 8(b) shows the corresponding AMSR2 RR field. RR values were retrieved from AMSR2 using formula (17). The pictures below illustrate the performance of RSS AMSR2 algorithm: Fig. 8(c) shows RSS AMSR2 RR, whereas Fig. 8(d) demonstrates the differences between RSS AMSR2 RR and RR, retrieved with the new approach. To calculate the differences, we gridded RR retrieved from Level 1B brightness temperature data onto RSS grid. Underestimation of RSS rain rates over the center of the typhoon by our method and prevailing overestimation of RSS at low rain rates can be concluded from Fig. 8(d). The scatter of the differences is within $4 \mathrm{~mm} / \mathrm{h}$. Fig. 8(e) and Fig. 8(d) are given to illustrate the performance of the WindSat all-weather algorithm: Fig. 8(e) presents WindSat SWS field at about 9:24 UTC, approximately 5 hour later AMSR2 acquisition time. Estimated maximum winds are about 36 m/s. Fig. 8(f) shows the corresponding WindSat RR field. It can be seen that the rain signature clearly manifests itself on the WindSat wind field whereas much weaker rain artifacts are observable in AMSR2 wind field in the south-west quadrant and to the east of the storm. 
Another example is given in Fig. 9, demonstrating SWS fields for the TC Rafael on 15 October 2012. Fig. 9(a) is $\mathrm{H}^{*}$ Wind field, built using the data of NOAA HRD at 19:30 UTC, whereas Fig. 9(b) is an AMSR2 SWS field at 18:00 UTC, shifted on the map so that the TC center corresponds to that of H*Wind.

$\mathrm{H}^{*}$ Wind data, presented as 1-minute winds at a spatial grid of $\sim 5.6 \times 5.6 \mathrm{~km}$, are the result of the objective analysis based on the assimilation and interpolation of all available storm wind observation data measured from various surface, aircraft and satellite platforms [32]. Most of these observations are scarce and taken over a long temporal window. These are the main reasons of $\mathrm{H}^{*}$ Wind field errors, discussed in more details in [58], [59]. Comparing AMSR2 SWS field with $\mathrm{H}^{*}$ Wind we need to be sure that the TC is well sampled by most reliable observations close in time with the AMSR2 path acquisition. Rafael H*Wind field on 15 October 2012 at 19:30 is based on a lot of data including representative data from 2 aircraft flights fitted with SFMR and dropsondes, moored buoys and ships. The area of high winds ( $>25 \mathrm{~m} / \mathrm{s}$ ) distinguished in the AMSR2 wind field to the south-east of the hurricane center, non-conformed with $\mathrm{H}^{*}$ Wind, seems to contain erroneous values due to high rain rates (Fig. 9(f) shows corresponding RSS AMSR2 rain rate field). There is a "tail" of a little bit higher (17-22 m/s) winds seen by ASCAT from Metop-A earlier (Fig. 9(c)) in the day at about 13:35 UTC. The ASCAT Level 2 Operational and Optimized Coastal Ocean Near-Real-Time ocean wind vector dataset (12.5-km resolution), provided by Royal Netherlands Meteorological Institute and processed at the Ocean and Sea Ice Satellite Application Facility, is used. The data were downloaded from the Physical Oceanography Distributed Active Archive Center (PO.DAAC) of NASA Jet Propulsion Laboratory. ASCAT winds for this area are lower than AMSR2 ones. But there are no grounds to judge how far from the truth AMSR2 or ASCAT winds since this area is not covered by in-situ reliable data. The RSS WindSat all-weather winds (Fig. 9(c)) are mostly masked. The area to the south-east of the hurricane center is not totally masked but the winds don't seem to be reliable for the comparison (non-physical high variations). The RSS AMSR2 rain rates (Fig. 9(f)) for this area are about 10-15 mm/h, RSS AMSR2 winds are totally 
masked (Fig. 9(e)). As for the AMSR2 wind over the center of the hurricane, there is generally good agreement with $\mathrm{H}^{*}$ Wind image, except for the streaking close to the core due to high rain rates.

Hurricane surface winds strongly depend on the measurement averaging time. AMSR2 spatial resolution is more consistent with 10-minite winds which are $~ 0.93 \%$ of 1 -minute winds [60], used in $\mathrm{H}^{*} \mathrm{Wind}$ analysis and reported by TC centers. This means that the demonstrated maximum wind correspondence can be due to general overestimation of 10-minute winds by the AMSR2 algorithm under high rain rates due to the underestimation of the rain radiance following from the numerical modeling results.

\section{VALIDATION AND DISCUSSION.}

To evaluate more quantitatively AMSR2 SWS algorithm performance in TCs, SMOS derived winds [13] have been compared with AMSR2 winds.

SMOS (Soil Moisture and Ocean Salinity) is the European Space Agency's water mission, an Earth Explorer Opportunity Mission belonging to its Living Planet Program, aiming to provide global and regular observations of soil moisture and sea surface salinity [61]. The SMOS radiometer elements operate at L-band ( 1.4 GHz). SMOS $T_{B}$ image is synthetically formed from simultaneous multiangular observations. These images of the brightness temperature are obtained over a large swath of $1200 \mathrm{~km}$ with a spatial resolution within the swath from $\sim 30 \mathrm{~km}$ to $\sim 80 \mathrm{~km}$. SMOS signatures are significantly less sensitive to rain than the other passive microwave radiometer $T_{B} \mathrm{~S}$, thus providing the capabilities to measure oceanic parameters in TCs under heavy precipitation. SMOS SWS were validated against SFMR data for several NOAA flights over TCs and can be considered as the first satellite “close to truth” winds [13].

Direct comparisons are complicated due to the differences in the AMSR2 and SMOS acquisition times. But some qualitative analysis is possible even when the time differences are large. For example the winds in the hurricane Leslie on 7 September 2012, retrieved at 6:00 UTC from AMSR2 data, are shown in Fig. 
10(a), aside to almost simultaneous RSS WindSat all-weather winds at 5:35 UTC. The maximum sustained winds on this day are reported by the NOAA National Hurricane Center to be about 33 m/s. AMSR2 maximum wind is $32.6 \mathrm{~m} / \mathrm{s}$. WindSat maximum wind is significantly less, about $25 \mathrm{~m} / \mathrm{s}$. This hurricane on 58 September is featured by very slow northward motion and almost steady intensity, with increasing circulation diameter. Two SMOS wind fields retrieved from the evening paths of 5 and 7 September are shown in Fig. 10(c) and (d), demonstrating the consistency with AMSR2 wind pattern in spite of 30 and 17 hour difference.

Typhoon Haiyan came upon the Philippines in November 2013 with maximum sustained winds of 85 $\mathrm{m} / \mathrm{s}$, making it one of the strongest tropical storms to date and the second-deadliest Philippine typhoon on record. By 6 November 2013, the JTWC assessed the Haiyan system as a Category 5-equivalent super typhoon on the Saffir-Simpson hurricane wind scale. The maximum intensity was reached on 7 November in the evening. SMOS intercepted Haiyan on the 7 Nov 2013 at 09:15 UTC while AMSR2 intercepted the Typhoon the same day about 5 hours sooner at $~ 4: 22$ UTC. To compare the surface wind speed retrieved from both sensors, we recentered the eye estimated from each sensor data set based on the location of the maximum wind. Comparisons between both sensor surface wind retrievals are shown in Fig. 11. They reveal that above hurricane force $(>33 \mathrm{~m} / \mathrm{s})$ both instruments see very similar wind speed structures. Major differences are observed in the lowest wind speed range below hurricane force. It can be due to temporal evolution of the wind field in between the two observations or to differences in the breaking wave, sea state, spray or other geophysical impact on the brightness temperatures.

To further validate the suggested approach for surface wind speed estimation from AMSR2 data we compared the results of SWS retrievals with SFMR estimated winds [16] for the case of hurricane Sandy on 29 October 2012 and for the hurricane Edouard on 15 September 2014. The wind speed fields retrieved from AMSR2 for these two hurricanes are shown in Fig. 12. 
SFMR data used for comparison with AMSR2 have been downloaded from the NOAA HRD AOML web site (http:// www.aoml.noaa.gov/ hrd/). SFMR wind observations correspond to 1-minute sustained winds [50]. Comparing AMSR2 winds, due to their spatial resolution corresponding to 10-minute winds, with SFMR winds, additional important aspects should be taken into account. First, aircraft flights over the tropical cyclones last for 5-10 hour whereas satellite microwave radiometer measurements which form a still “image” of a cyclone are taken within a few minutes. Air flights are scheduled to investigate the cyclone development and often follow the cyclone track, several times overpassing the eye walls. Second, the SFMR wind speed profiles along the aircraft tracks are highly resolved spatially $(\sim 3 \times 1 \mathrm{~km}[62])$ in contrast to AMSR2 products with a spatial resolution at the lowest frequency channels of $\sim(35 \times 61 \mathrm{~km})$. For the comparisons, we used only those SFMR data which were acquired within 0.5 hour difference from AMSR2 acquisition.

Fig. 13 illustrates AMSR2 derived surface wind speed contour plot over Sandy at 18:15 UTC with a superimposed track of the United States Air Force (USAF) 53d Weather Reconnaissance Squadron (WRS) Flight 308 equipped with an SMFR instrument. Fig. 13 (a) shows SFMR winds whereas Fig. 13 (b) indicates SFMR measurement UTC time evolution during the aircraft flight. The black polygonal lines show the TC eye track during 29 October with a relatively fast forward translation speed of about $40 \mathrm{~km} / \mathrm{h}$ during that day.

SFMR and AMSR2 retrieved wind speeds interpolated along the aircraft track are shown in Fig. 14 as function of time. As illustrated, close to AMSR2 acquisition time at about 18:15 UTC the AMSR2 retrieved winds along the track are in good agreement with the SFMR ones. Around 17:25-17:35, 17:45 and 19:15 UTC the aircraft flew across the hurricane eye with low wind speeds smoothed by AMSR2 coarse resolution. Observed differences between AMSR2 and SFMR winds for time differences larger than half an hour can be both due to the cyclone wind and rain structures evolution. The root mean square difference $\sigma$ 
between SFMR and AMSR2 winds for the considered time range is $1.3 \mathrm{~m} / \mathrm{s}$. The maximum wind speed estimated by AMSR2 is $35.5 \mathrm{~m} / \mathrm{s}$, the maximum wind speed estimated by SFMR is $36.0 \mathrm{~m} / \mathrm{s}$.

The second case we consider here involves co-localized SFMR/AMSR2 observations during Hurricane Edouard in the evening of 15 September 2014. At the time of both acquisitions, the TC forward translation speed was about $20 \mathrm{~km} / \mathrm{h}$, almost twice slower than for the case of Sandy. Fig. 15 shows AMSR2 SWS contour plot over Edouard at about 16:45 UTC with a superimposed track of the NOAA Aircraft 43RF that was equipped with an SMFR instrument. SFMR data are plotted over AMSR2 winds in Fig. 15 (a) and the SFMR measurement times are also given in Fig 15 (b). The co-localized winds along with SFMR rain rate are also presented in Fig. 16. In general, AMSR2 winds agree very well with SFMR ones except in the low winds region around the cyclone center. It can be seen that within half an hour difference before and after AMSR2 acquisition time, SFMR and AMSR2 winds agree well (with a $\sigma$ of $1.2 \mathrm{~m} / \mathrm{s}$ ) except that the SFMR wind speed drop at 16:25 UTC is not distinguished in AMSR2 winds due to spatial smoothing. This drop is associated with the aircraft crossing the cyclone center (its south boundary is marked by $\times$ in Fig. 15(a)). The aircraft flew over the center from 16:20 till 16:28, measuring wind speeds in the range 13.4 to $39.7 \mathrm{~m} / \mathrm{s}$ reached at the northern eyewall and up to $47.8 \mathrm{~m} / \mathrm{s}$ south of the eye center. The consistency between the maximum winds estimated from AMSR2 $(48.3 \mathrm{~m} / \mathrm{s})$ and from SFMR $(47.8 \mathrm{~m} / \mathrm{s})$ data south of the eye center is remarkable given the high rain rates reaching up to $30 \mathrm{~mm} / \mathrm{h}$ as detected with SFMR.

Despite differing sampling characteristics between SFMR and AMSR2 sensors, the comparison of the aircraft and satellite-based SWS measurements for the two flights over the two selected tropical cyclones has demonstrated their high correlation within half an hour time difference with a total root mean square error as low as $1.3 \mathrm{~m} / \mathrm{s}$ within a range from 16.5 up to $40 \mathrm{~m} / \mathrm{s}$. Near the collocation time AMSR2 winds are generally lower than SFMR winds due to spatial smoothing. The maximum winds estimated by SFMR and AMSR2 differ as little as $0.5 \mathrm{~m} / \mathrm{s}$ for both considered cyclones. This means, taking into account the 
difference in AMSR2 and SFMR spatial resolution, an overestimation of SFMR maximum winds by the AMSR2 algorithm.

\section{CONCLUSION}

A method to estimate sea surface wind speeds under extreme conditions of tropical cyclones using GCOM-W1 AMSR2 measurements in C- and X-bands is described and tested. Initially designated for RFI detection, the additional AMSR2 channels in C-band can indeed be exploited to help in separating raininduced $\mathrm{T}_{\mathrm{B}}$ from non-rain atmosphere-ocean $\mathrm{T}_{\mathrm{B}}$.

As such, AMSR2 measurements can be used to retrieve SWSs, even under rain conditions occurring during TCs. Spatial and temporal collocation of AMSR2 and TRMM TMI is then further used to empirically relate TMI rain rate product to RR estimates from AMSR2 in hurricanes.

The resulting SWS fields have been obtained for 110 Atlantic and Pacific TCs intercepted by AMSR2 swath over the period 2012-2014, and compared to data from the Japan Meteorological Agency, archived by the Joint Typhoon Warning Center (JTWC), and the NOAA's Hurricane Research Division (HRD), processed by the Atlantic Oceanographic \& Meteorological Laboratory (AOML). Most of the retrieved wind speed fields proved to well match TC center estimates in terms of maximum wind speeds, radii of storm and hurricane winds although some cases, associated with high RR values, indicated considerable discrepancy. Since AMSR2 SWS spatial resolution better corresponds to 10-minute winds we can conclude that TC center maximum 1-munite winds are overestimated by the suggested algorithm. Results further include comparisons between AMSR2 and SMOS wind speeds to demonstrate high consistency between the wind field structures derived from both sensor. As SMOS measurements are very weakly influenced by rain, this overall agreement between two independent datasets provides additional confidence in the proposed methodology. Additional validation with highly accurate in TCs SFMR winds also substantiates the approach, though demonstrating some overestimation of maximum winds in TCs. 
Further studies are certainly needed to investigate the possible influence of the wind field asymmetry and very strong precipitation on the SWS algorithm performance. As envisaged, cases of “weak" algorithm performance will benefit from the joint analysis of GCOM-W1 AMSR2, GPM Microwave Imager and Double Precipitation Radar, and also from high resolution active cross-polarized microwave measurements available from Sentinel-1 and RadarSat-2 SAR data acquired over TCs.

\section{ACKNOWLEDGMENT}

This research was supported by the Mega-grant of the Russian Federation Government to support scientific research under the supervision of leading scientist at RSHU, No. 11.G34.31.0078, ESA Support to Science (SMOS+Storm Evolution project), Russian Fond for Basic Research Project 14-05-91760-AF_a and Ministry of Education and Science of the Russian Federation Project through the Projects 2498 and RFMEFI61014X0006, agreement \#14.610.21.0006 and Japan Aerospace Exploration Agency Project F10.

\section{REFERENCES}

[1] Y. Quilfen, C. Prigent, B. Chapron, A. A. Mouche, and N. Houti, “The potential of QuikSCAT and WindSat observations for the estimation of sea surface wind vector under severe weather conditions,” J. Geophys. Res., vol. 112, no. C09023, 2007.

[2] Y. Quilfen, B. Chapron, and J. Tournadre, "Satellite Microwave Surface Observations in Tropical Cyclones,” Mon. Weather Rev., vol. 138, no. 2, pp. 421-437, Feb. 2010.

[3] L. Ricciardulli, T. Meissner, and F. Wentz, “Towards a Climate Data Record of satellite ocean vector winds,” in Geoscience and Remote Sensing Symposium (IGARSS), 2012 IEEE International, 2012, pp. 2067-2069.

[4] K. B. Katsaros, L. Mitnik, and P. Black, "Microwave Instruments for Observing Tropical Cyclones,” 
in Typhoon Impact and Crisis Management, Springer, 2014, pp. 5-61.

[5] W. J. Donnelly, J. R. Carswell, R. E. McIntosh, P. S. Chang, J. Wilkerson, F. Marks, and P. G. Black, "Revised ocean backscatter models at C and Ku band under high-wind conditions,” J. Geophys. Res. Oceans, vol. 104, no. C5, pp. 11485-11497, 1999.

[6] G.-J. van Zadelhoff, A. Stoffelen, P. W. Vachon, J. Wolfe, J. Horstmann, and M. Belmonte Rivas, “Scatterometer hurricane wind speed retrievals using cross polarization,” Atmospheric Meas. Tech. Discuss., vol. 6, pp. 7945-7984, 2013.

[7] B. Zhang, W. Perrie, J. A. Zhang, E. W. Uhlhorn, and Y. He, "High Resolution Hurricane Vector Winds from C-band Dual-Polarization SAR Observations,” J. Atmospheric Ocean. Technol., Nov. 2013.

[8] B. Zhang and W. Perrie, “Cross-Polarized Synthetic Aperture Radar: A New Potential Measurement Technique for Hurricanes,” Bull. Am. Meteorol. Soc., vol. 93, no. 4, pp. 531-541, Apr. 2012.

[9] S. H. Yueh, B. W. Stiles, and W. T. Liu, “QuikSCAT wind retrievals for tropical cyclones,” IEEE Trans. Geosci. Remote Sens., vol. 41, no. 11, pp. 2616-2628, 2003.

[10] N. Reul and B. Chapron, “A model of sea-foam thickness distribution for passive microwave remote sensing applications,” J. Geophys. Res. Oceans, vol. 108, no. C10, 2003.

[11] A. Stogryn, “The emissivity of sea foam at microwave frequencies,” J. Geophys. Res., vol. 77, no. 9, pp. 1658-1666, 1972.

[12] M. D. Anguelova and P. W. Gaiser, "Dielectric and Radiative Properties of Sea Foam at Microwave Frequencies: Conceptual Understanding of Foam Emissivity,” Remote Sens., vol. 4, no. 5, pp. 11621189, Apr. 2012.

[13] N. Reul, J. Tenerelli, B. Chapron, D. Vandemark, Y. Quilfen, and Y. Kerr, "SMOS satellite L-band radiometer: A new capability for ocean surface remote sensing in hurricanes,” J. Geophys. Res. Oceans 1978-2012, vol. 117, no. C2, 2012. 
[14] L. H. Holthuijsen, M. D. Powell, and J. D. Pietrzak, "Wind and waves in extreme hurricanes,” J. Geophys. Res. Oceans, vol. 117, no. C9, p. C09003, Sep. 2012.

[15] S. Soisuvarn, Z. Jelenak, and W. L. Jones, “An Ocean Surface Wind Vector Model Function for a Spaceborne Microwave Radiometer,” IEEE Trans. Geosci. Remote Sens., vol. 45, no. 10, pp. 31193130, 2007.

[16] E. W. Uhlhorn, P. G. Black, J. L. Franklin, M. Goodberlet, J. Carswell, and A. S. Goldstein, “Hurricane surface wind measurements from an operational stepped frequency microwave radiometer,” Mon. Weather Rev., vol. 135, no. 9, pp. 3070-3085, 2007.

[17] T. Meissner and F. J. Wentz, “The emissivity of the ocean surface between 6 and $90 \mathrm{GHz}$ over a large range of wind speeds and earth incidence angles,” IEEE Trans. Geosci. Remote Sens., vol. 50, no. 8, pp. 3004-3026, 2012.

[18] N. Skou and D. Hoffman-Bang, "L-band radiometers measuring salinity from space: atmospheric propagation effects,” IEEE Trans. Geosci. Remote Sens., vol. 43, no. 10, pp. 2210-2217, Oct. 2005.

[19] F. J. Wentz and T. Meissner, “Algorithm Theoretical Basis Document (ATBD), Version 2, AMSR Ocean Algorithm, RSS Tech. Proposal 121599A-1, Remote Sensing Systems,” Algorithm Theor. Basis Doc. ATBD Version 2 AMSR Ocean Algorithm RSS Tech Propos. 121599A-1 Remote Sens. Syst., 2000.

[20] L. M. Mitnik, M. L. Mitnik, and E. V. Zabolotskikh, "Microwave sensing of the atmosphere-ocean system with ADEOS-II AMSR and Aqua AMSR-E,” J. Remote Sens. Soc. Jpn. Jpn., 2009.

[21] T. Meissner and F. J. Wentz, "Wind-Vector Retrievals Under Rain With Passive Satellite Microwave Radiometers,” IEEE Trans. Geosci. Remote Sens., vol. 47, no. 9, pp. 3065-3083, 2009.

[22] D. Kim and D. R. Lyzenga, “Efficient Model-Based Estimation of Atmospheric Transmittance and Ocean Wind Vectors From WindSat Data,” IEEE Trans. Geosci. Remote Sens., vol. 46, no. 8, pp. 2288-2297, Aug. 2008. 
[23] D. E. Weissman, B. W. Stiles, S. M. Hristova-Veleva, D. G. Long, D. K. Smith, K. A. Hilburn, and W. L. Jones, “Challenges to Satellite Sensors of Ocean Winds: Addressing Precipitation Effects,” J. Atmospheric Ocean. Technol., vol. 29, no. 3, pp. 356-374, Mar. 2012.

[24] D. E. Weissman and M. A. Bourassa, “The influence of rainfall on scatterometer backscatter within tropical cyclone environments-Implications on parameterization of sea-surface stress,” Geosci. Remote Sens. IEEE Trans. On, vol. 49, no. 12, pp. 4805-4814, 2011.

[25] V. Raizer, “Macroscopic Foam-Spray Models for Ocean Microwave Radiometry,” IEEE Trans. Geosci. Remote Sens., vol. 45, no. 10, pp. 3138-3144, 2007.

[26] M. Yamasaki, “A Study on the Effects of the Ice Microphysics on Tropical Cyclones,” Adv. Meteorol., vol. 2013, p. e573786, May 2013.

[27] A. O. Fierro, L. Leslie, E. Mansell, J. Straka, D. MacGorman, and C. Ziegler, “A high-resolution simulation of microphysics and electrification in an idealized hurricane-like vortex,” Meteorol. Atmospheric Phys., vol. 98, no. 1-2, pp. 13-33, 2007.

[28] M. H. Bettenhausen, C. K. Smith, R. M. Bevilacqua, N.-Y. Wang, P. W. Gaiser, and S. Cox, “A nonlinear optimization algorithm for WindSat wind vector retrievals,” IEEE Trans. Geosci. Remote Sens., vol. 44, no. 3, pp. 597-610, 2006.

[29] F. J. Wentz, “A well-calibrated ocean algorithm for special sensor microwave/imager,” J Geophys Res, vol. 102, pp. 8703-8718, 1997.

[30] A. Shibata, “A wind speed retrieval algorithm by combining 6 and $10 \mathrm{GHz}$ data from Advanced Microwave Scanning Radiometer: Wind speed inside hurricanes,” J. Oceanogr., vol. 62, no. 3, pp. 351-359, 2006.

[31] C. Kummerow and R. Ferraro, “Algorithm Theoretical Basis Document: EOS/AMSR-E Level-2 Rainfall,” Colo. State Univ. Rep., pp. 1-10, 2007.

[32] M. D. Powell, S. H. Houston, L. R. Amat, and N. Morisseau-Leroy, "The HRD real-time hurricane 
wind analysis system,” J. Wind Eng. Ind. Aerodyn., vol. 77, pp. 53-64, 1998.

B. W. Klotz and E. W. Uhlhorn, "Improved Stepped Frequency Microwave Radiometer Tropical Cyclone Surface Winds in Heavy Precipitation,” J. Atmospheric Ocean. Technol., vol. 31, no. 11, pp. 2392-2408, Nov. 2014.

[34] M. D. Powell, S. Murillo, P. Dodge, E. Uhlhorn, J. Gamache, V. Cardone, A. Cox, S. Otero, N. Carrasco, and B. Annane, "Reconstruction of Hurricane Katrina's wind fields for storm surge and wave hindcasting,” Ocean Eng., vol. 37, no. 1, pp. 26-36, 2010.

[35] K. Imaoka, M. Kachi, H. Fujii, H. Murakami, M. Hori, A. Ono, T. Igarashi, K. Nakagawa, T. Oki, Y. Honda, and others, "Global Change Observation Mission (GCOM) for monitoring carbon, water cycles, and climate change,” Proc. IEEE, vol. 98, no. 5, pp. 717-734, 2010.

[36] P. Bauer and P. Schluessel, "Rainfall, total water, ice water, and water vapor over sea from polarized microwave simulations and Special Sensor Microwave/Imager data,” J. Geophys. Res., vol. 98, no. D11, pp. 20737-20759, 1993.

[37] C. Kummerow, W. S. Olson, and L. Giglio, "A simplified scheme for obtaining precipitation and vertical hydrometeor profiles from passive microwave sensors,” IEEE Trans. Geosci. Remote Sens., vol. 34, no. 5, pp. 1213-1232, 1996.

[38] B. Lin and W. B. Rossow, "Precipitation water path and rainfall rate estimates over oceans using special sensor microwave imager and International Satellite Cloud Climatology Project data,” $J$. Geophys. Res., vol. 102, no. D8, pp. 9359-9374, 1997.

[39] C. Surussavadee and D. H. Staelin, "Millimeter-wave precipitation retrievals and observed-versussimulated radiance distributions: Sensitivity to assumptions,” J. Atmospheric Sci., vol. 64, no. 11, pp. 3808-3826, 2007.

[40] F. J. Wentz, “A model function for ocean microwave brightness temperatures,” J Geophys Res, vol. 88, no. C3, pp. 1892-1908, 1983. 
[41] D. Deirmendjian, "Far infrared and submillimeter wave attenuation by clouds and rain," DTIC Document, 1975.

[42] E. Zabolotskikh, L. Mitnik, and B. Chapron, “GCOM-W1 AMSR2 and MetOp-A ASCAT wind speeds for the extratropical cyclones over the North Atlantic,” Remote Sens. Environ., vol. 147, pp. 89-98, May 2014.

[43] E. Zabolotskikh, L. Mitnik, and B. Chapron, “An Updated Geophysical Model for AMSR-E and SSMIS Brightness Temperature Simulations over Oceans,” Remote Sens., vol. 6, no. 3, pp. 23172342, 2014.

[44] E. V. Zabolotskikh, L. M. Mitnik, and B. Chapron, "New approach for severe marine weather study using satellite passive microwave sensing,” Geophys. Res. Lett., vol. 40, no. 13, pp. 3347-3350, 2013.

[45] “GCOM-W1 Data Providing Service Users Manual.” Japan Aerospace Exploration Agency, 2013.

[46] “MODIS Level 1B Product User's Guide For Level 1B Version 5.0.6 (Terra) and Version 5.0.7 (Aqua).” 2006.

[47] A. K. Liu, S. He, Y. Pan, and J. Yang, “Observations of typhoon eye using SAR and IR sensors,” Int. J. Remote Sens., vol. 35, no. 11-12, pp. 3966-3977, 2014.

[48] H. Jiang, E. M. Ramirez, and D. J. Cecil, "Convective and Rainfall Properties of Tropical Cyclone Inner Cores and Rainbands from 11 Years of TRMM Data,” Mon. Weather Rev., vol. 141, no. 2, pp. 431-450, Feb. 2013.

[49] N. Duffo, A. Camps, I. Corbella, and F. Torres, "Polarimetric emission of rain events: simulation and experimental results at X-Band,” Remote Sens., vol. 1, no. 2, pp. 107-121, 2009.

[50] E. W. Uhlhorn, B. W. Klotz, T. Vukicevic, P. D. Reasor, and R. F. Rogers, “Observed hurricane wind speed asymmetries and relationships to motion and environmental shear,” Mon. Weather Rev., vol. 142, no. 3, pp. 1290-1311, 2014. 
[51] H. J. Liebe and D. H. Layton, “Millimeter-wave properties of the atmosphere: Laboratory studies and propagation modeling,” Nat. Tech. Inf. Service Boulder, CO, NTIA Rep. 87-24, 1987.

[52] S. Y. Matrosov and E. M. Shulgina, "Scattering and attenuation of microwave radiation by precipitation,” MGO Trans., vol. 448, pp. 85-94, 1982.

[53] L. M. Mitnik and M. L. Mitnik, "Retrieval of atmospheric and ocean surface parameters from ADEOS-II Advanced Microwave Scanning Radiometer (AMSR) data: Comparison of errors of global and regional algorithms,” Radio Sci., vol. 38, no. 4, p. 8065, 2003.

[54] K. A. Hilburn and F. J. Wentz, "Intercalibrated passive microwave rain products from the unified microwave ocean retrieval algorithm (UMORA),” J. Appl. Meteorol. Climatol., vol. 47, no. 3, pp. 778-794, 2008.

[55] K. Imaoka, T. Maeda, M. Kachi, M. Kasahara, N. Ito, and K. Nakagawa, "Status of AMSR2 instrument on GCOM-W1,” presented at the Proc. SPIE 8528, Earth Observing Missions and Sensors: Development, Implementation, and Characterization II, 852815, 2012, vol. 8528, pp. $15-21$.

[56] A. Y. Hou, R. K. Kakar, S. Neeck, A. A. Azarbarzin, C. D. Kummerow, M. Kojima, R. Oki, K. Nakamura, and T. Iguchi, “The Global Precipitation Measurement (GPM) Mission,” Bull. Am. Meteorol. Soc., vol. 95, no. 5, pp. 711-722, 2014.

[57] M. Aksoy and J. T. Johnson, “A Comparative Analysis of Low-Level Radio Frequency Interference in SMOS and Aquarius Microwave Radiometer Measurements,” IEEE Trans. Geosci. Remote Sens., vol. 51, no. 10, pp. 4983-4992, 2013.

[58] I. S. Adams, C. C. Hennon, W. L. Jones, and K. A. Ahmad, "Evaluation of hurricane ocean vector winds from WindSat,” IEEE Trans. Geosci. Remote Sens., vol. 44, no. 3, pp. 656-667, 2006.

[59] S. H. Yueh, "Directional signals in Windsat observations of hurricane ocean winds," Geosci. Remote Sens. IEEE Trans. On, vol. 46, no. 1, pp. 130-136, 2008.

[60] B. A. Harper, J. D. Kepert, and J. D. Ginger, "Guidelines for converting between various wind 
averaging periods in tropical cyclone conditions,” World Meteor Org TCP Sub-Proj. Rep. WMOTD, no. 1555, 2010.

[61] Y. H. Kerr, P. Waldteufel, J.-P. Wigneron, S. Delwart, F. Cabot, J. Boutin, M.-J. Escorihuela, J. Font, N. Reul, C. Gruhier, S. E. Juglea, M. R. Drinkwater, A. Hahne, M. Martin-Neira, and S. Mecklenburg, "The SMOS Mission: New Tool for Monitoring Key Elements ofthe Global Water Cycle,” Proc. IEEE, vol. 98, no. 5, pp. 666-687, May 2010.

[62] E. W. Uhlhorn and D. S. Nolan, "Observational undersampling in tropical cyclones and implications for estimated intensity,” Mon. Weather Rev., vol. 140, no. 3, pp. 825-840, 2012.

\section{Figure captions}

Figure 1. Brightness temperature fields in K measured by AMSR2 at $10.65 \mathrm{GHz}$, vertical polarization (a) on 7 November 2013 at $\sim$ 4:20 UTC over the typhoon Haiyan and (b) on 7 October 2013 at $\sim$ 17:15 UTC over the typhoon Danas. Arcs A, and B marked by dark green line, indicate rain-free footprints.

Figure 2. Brightness temperature fields (K) measured by AMSR2 at $89 \mathrm{GHz}$, vertical polarization (a) on 7 November 2013 at $\sim$ 4:20 UTC over the typhoon Haiyan and (b) on 7 October 2013 at $\sim$ 17:15 UTC over the typhoon Danas. Arcs A, and B marked by dark green line, indicate rain-free footprints.

Figure 3. The differences between TB0, calculated according to (14), and TBAOS, calculated according to (12), at SWS $=20 \mathrm{~m} / \mathrm{s}$, as functions of the rain rate R for 6.9 and $10.65 \mathrm{GHz}$, horizontal and vertical polarization.

Figure 4. The differences in the calculated values of the downwelling part of $T B R$ at SWS $=0 \mathrm{~m} / \mathrm{s}$ and SWS $=40 \mathrm{~m} / \mathrm{s}$ as functions of the rain rate $\mathrm{R}$ at 6.9 and $10.65 \mathrm{GHz}$, horizontal and vertical polarization. 
Figure 5. (a) TMI rain rate field (mm/h) for the typhoon Danas on 7 October 2013 (http://www.remss.com/) at 18:36 UTC; (b). AMSR2 derived rain brightness temperature at $10.65 \mathrm{GHz}$ vertical polarization $(\mathrm{K})$ at $~ 17: 14$ UTC. Red dots indicate the center of the typhoon at $\sim 17: 14$ UTC

Figure 6. TMI RR versus AMSR2 derived rain brightness temperature at $10.65 \mathrm{GHz}$ vertical polarization

Figure 7. Sea surface wind speeds for the typhoon Danas on 7 October 2013: (a) derived from AMSR2 at 17:15 UTC; (b) RSS WindSat all-weather SWS at 21:36 UTC.

Figure 8. Typhoon Halong in the morning of 4 August 2014: (a) AMSR2 retrieved SWS at 04:36 UTC; (b) AMSR2 retrieved RR at 04:36 UTC; (c) Remote Sensing Systems AMSR2 RR at the same time; (d) the difference between RSS AMSR2 RR and retrieved AMSR2 RR; (e) RSS WindSat allweather SWS at 9:24 UTC; (f) RSS WindSat RR at 9:24 UTC.

Figure 9. The hurricane Rafael on 15 October 2012: (a) NOAA HRD H*Wind sea surface wind speed field (m/s) at 19:30; (b) AMSR2 SWS at 18:00 UTC; (c) Metop ASCAT SWS at 13:35 UTC; (d) RSS WindSat all-weather SWS at 21:50 UTC; (e) RSS AMSR2 SWS at 18:00 UTC and (f) RSS AMSR2 RR at 18:00.

Figure 10. Sea surface wind speeds in the hurricane Leslie: (a) retrieved from AMSR2 on 7 September 2012 at 6:00 UTC; (b) RSS WindSat all-weather winds on 7 September 2012 at 5:35 UTC; (c) retrieved from SMOS on 5 September 2012 at 22:00 UTC; (d) retrieved from SMOS on 7 September 2012 at 22:20 UTC.

Figure 11. East-West (a) and North-South (b) sections of the retrieved wind speed through the super Typhoon Haiyan on the 7 November 2013 (blue=SMOS; red=AMSR2). AMSR2 storm intercept is at 4:22 UTC, SMOS time intercept is at 9:15 UTC.

Figure 12. (a) AMSR2 retrieved sea surface wind speed (SWS) field in the hurricane Sandy on 29 October 2012 at 18:15 UTC; (b) AMSR2 SWS field in the hurricane Edouard on 15 September 2014 at 16:45 UTC. The black lines show the hurricane tracks. 
Figure 13. AMSR2 SWS contour plots for the hurricane Sandy on 29 October 2012 at 18:15 UTC with (a) superimposed SMFR winds from USAF 53 WRS Flight and (b) SMFR measurement time in UTC. The black polygonal lines show Sandy track.

Figure 14. AMSR2 retrieved surface wind speed (blue) and SFMR wind speed (red) in m/s and SFMR rain rate in $\mathrm{mm} / \mathrm{h}$ as functions of time along the USAF 53 WRS Flight aircraft flight track on 29 October 2012. Vertical dashed line indicates time of AMSR2 overpass of Sandy at 18:15 UTC.

Figure 15. AMSR2 SWS contour plots for the hurricane Edouard on 15 September 2014 at 16:45 UTC with (a) superimposed SMFR winds from NOAA Aircraft 43RF and (b) SMFR measurement time in UTC. The black polygonal lines show Edouard track.

Figure 16. AMSR2 retrieved surface wind speed (blue) and SFMR wind speed (red) in m/s and SFMR rain rate in $\mathrm{mm} / \mathrm{h}$ as functions of time along the NOAA Aircraft 43 Research Flight track on 15 September 2014. Vertical dashed line indicates time of AMSR2 overpass of the hurricane Edouard at 16:45 UTC. 


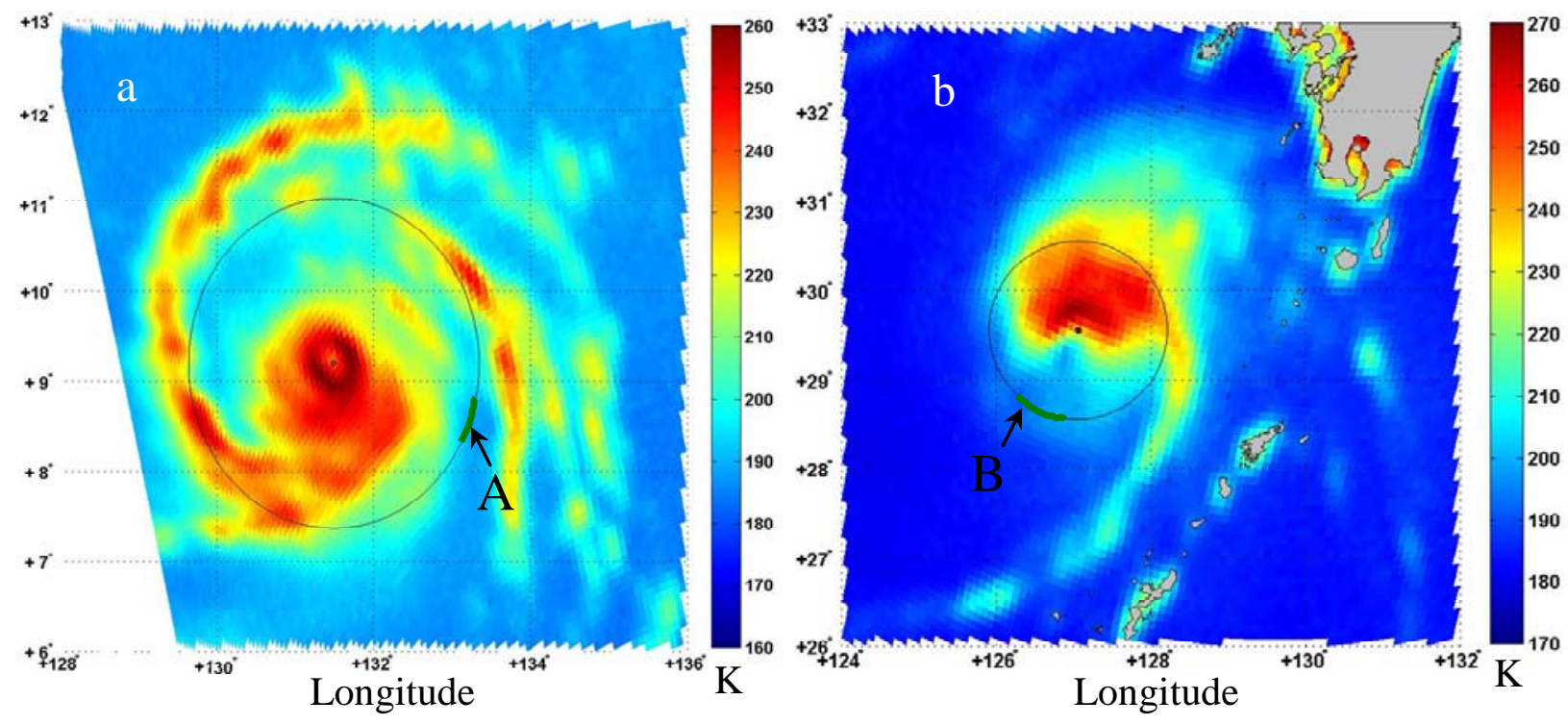

Zabolotskikh, Fig.1 


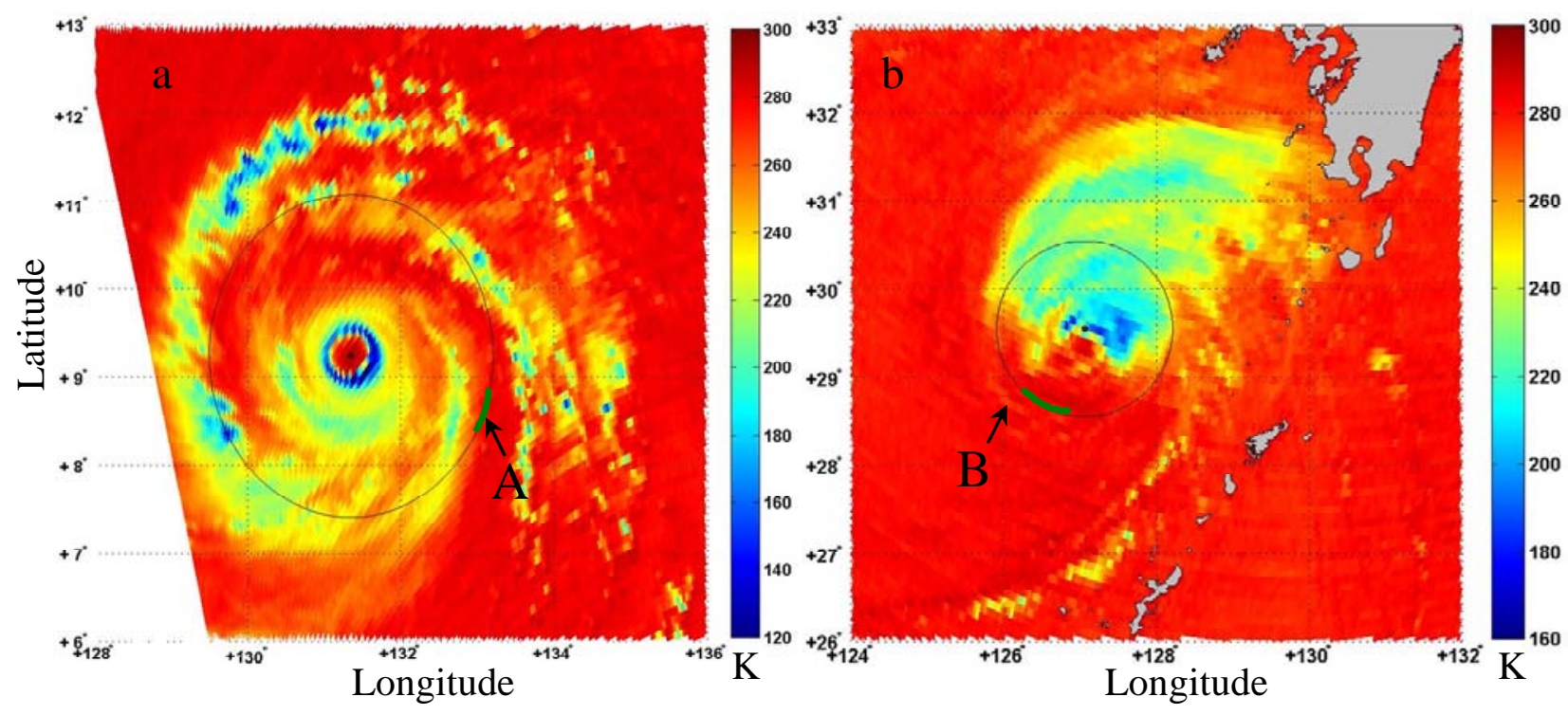

Zabolotskikh, Fig.2 


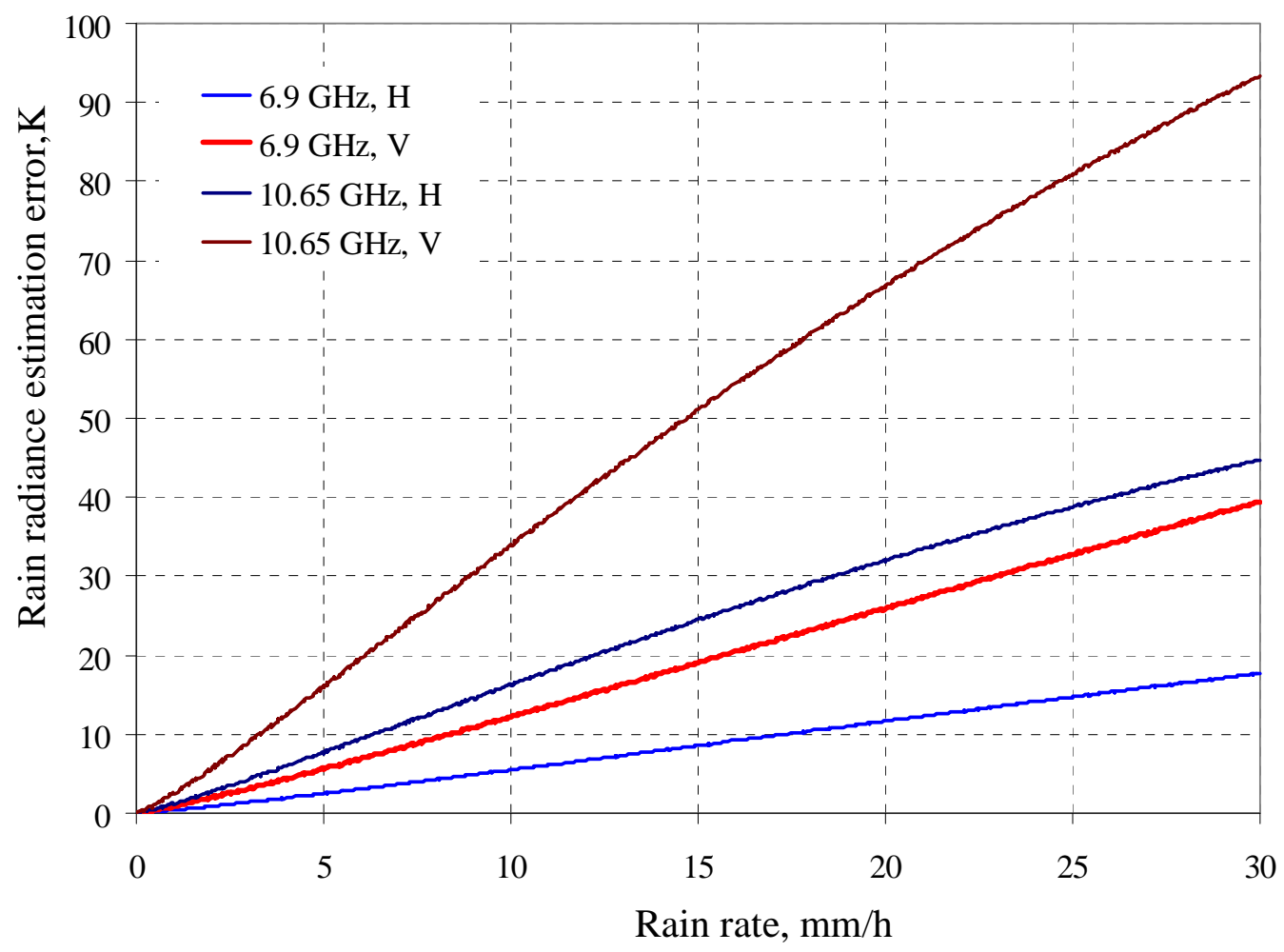

Zabolotskikh, Fig.3 


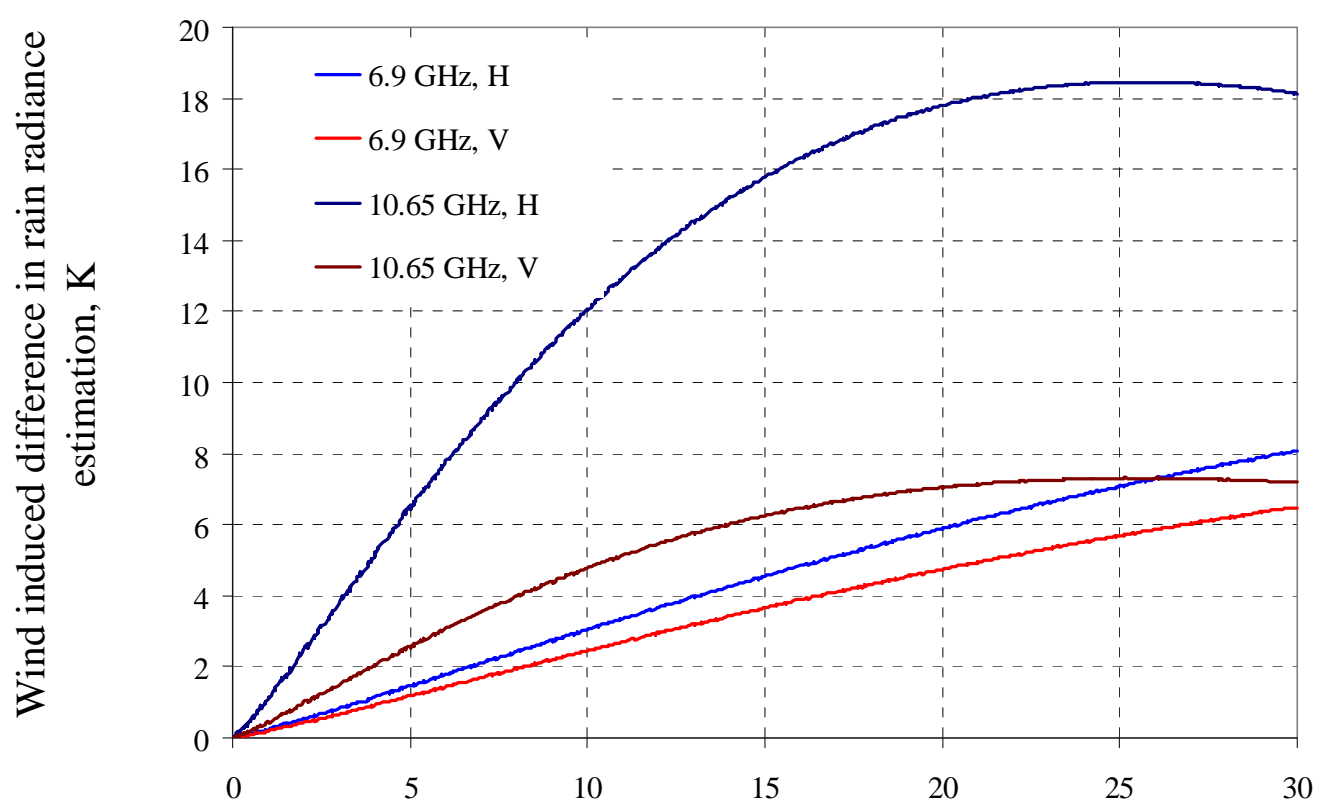

Rain rate, $\mathrm{mm} / \mathrm{h}$

Zabolotskikh, Fig.4 

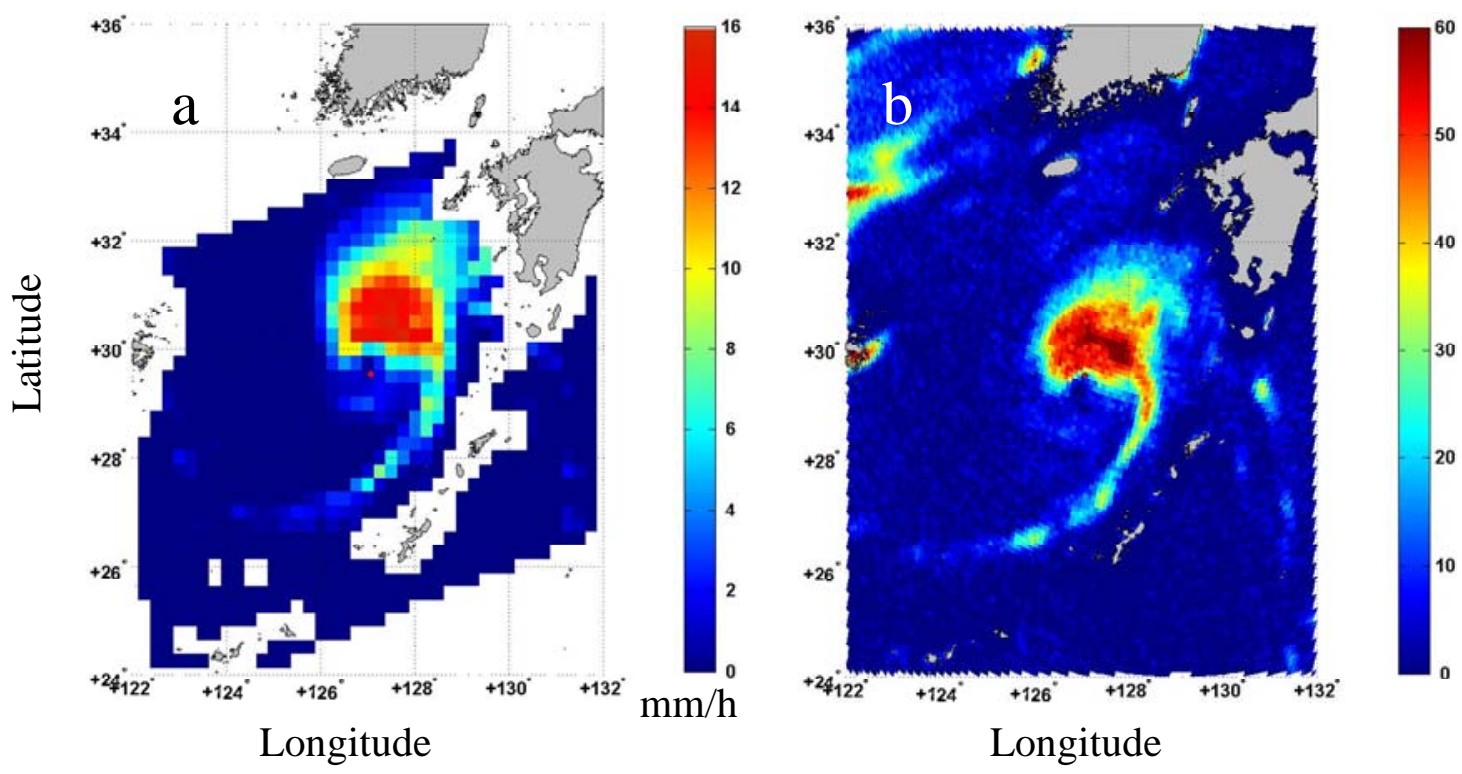

Zabolotskikh, Fig.5 


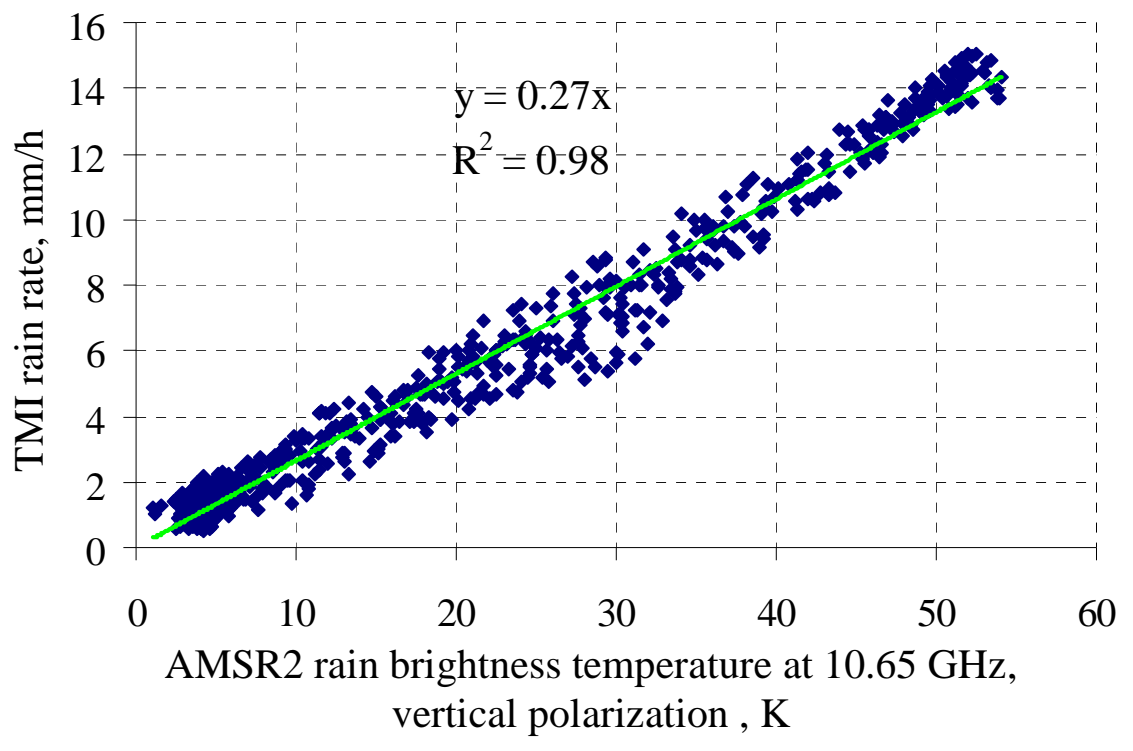

Zabolotskikh, Fig.6 


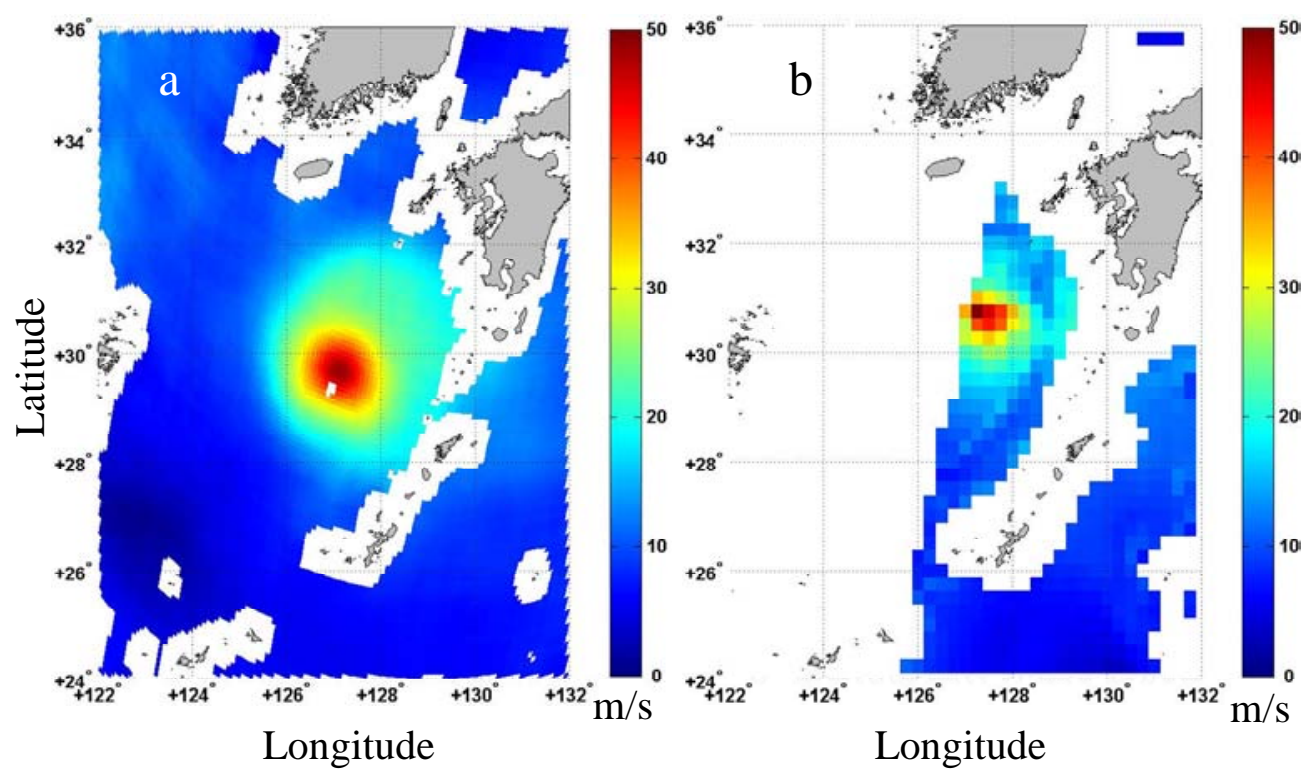

Zabolotskikh, Fig.7 

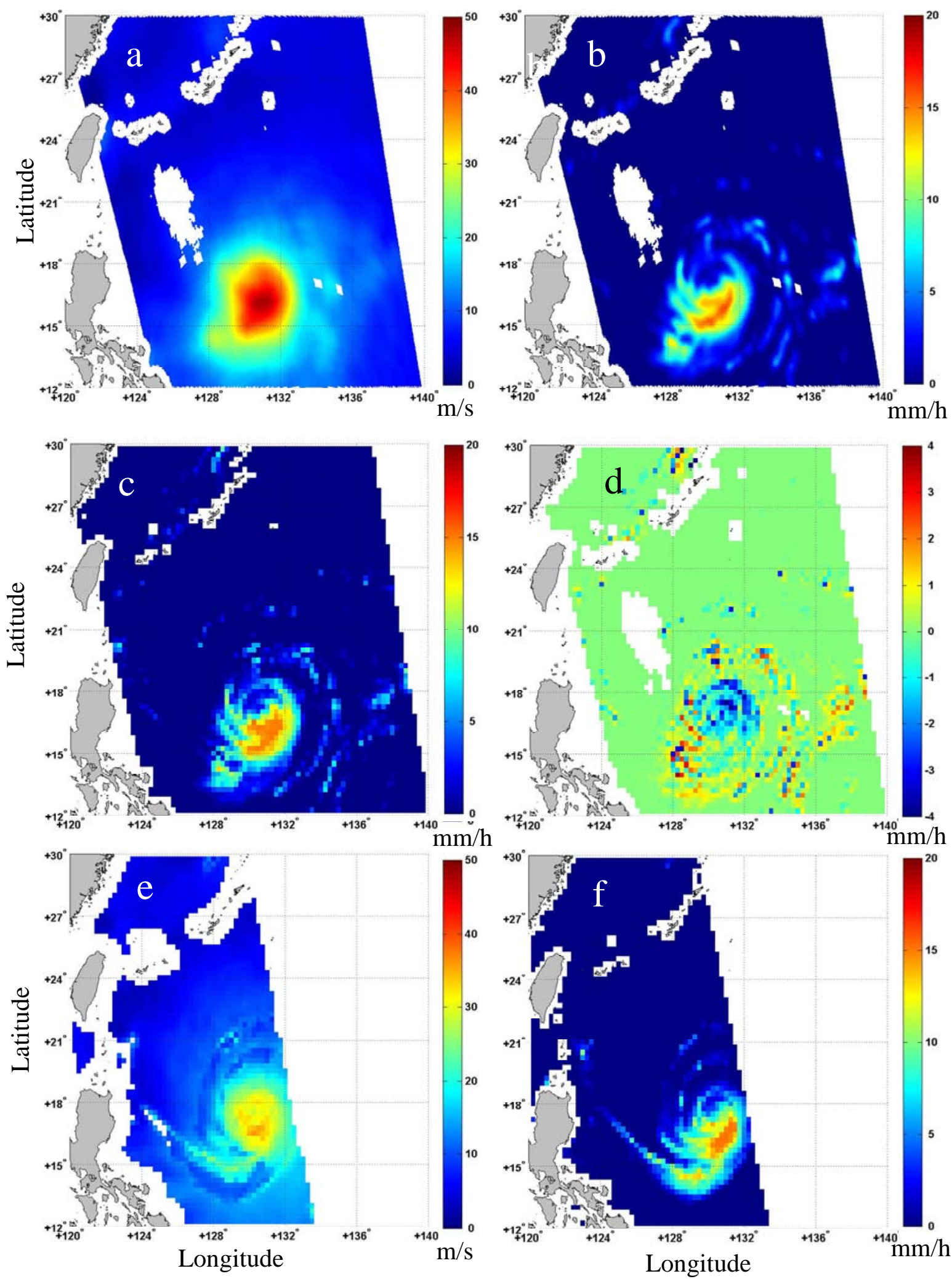

Zabolotskikh, Fig.8 

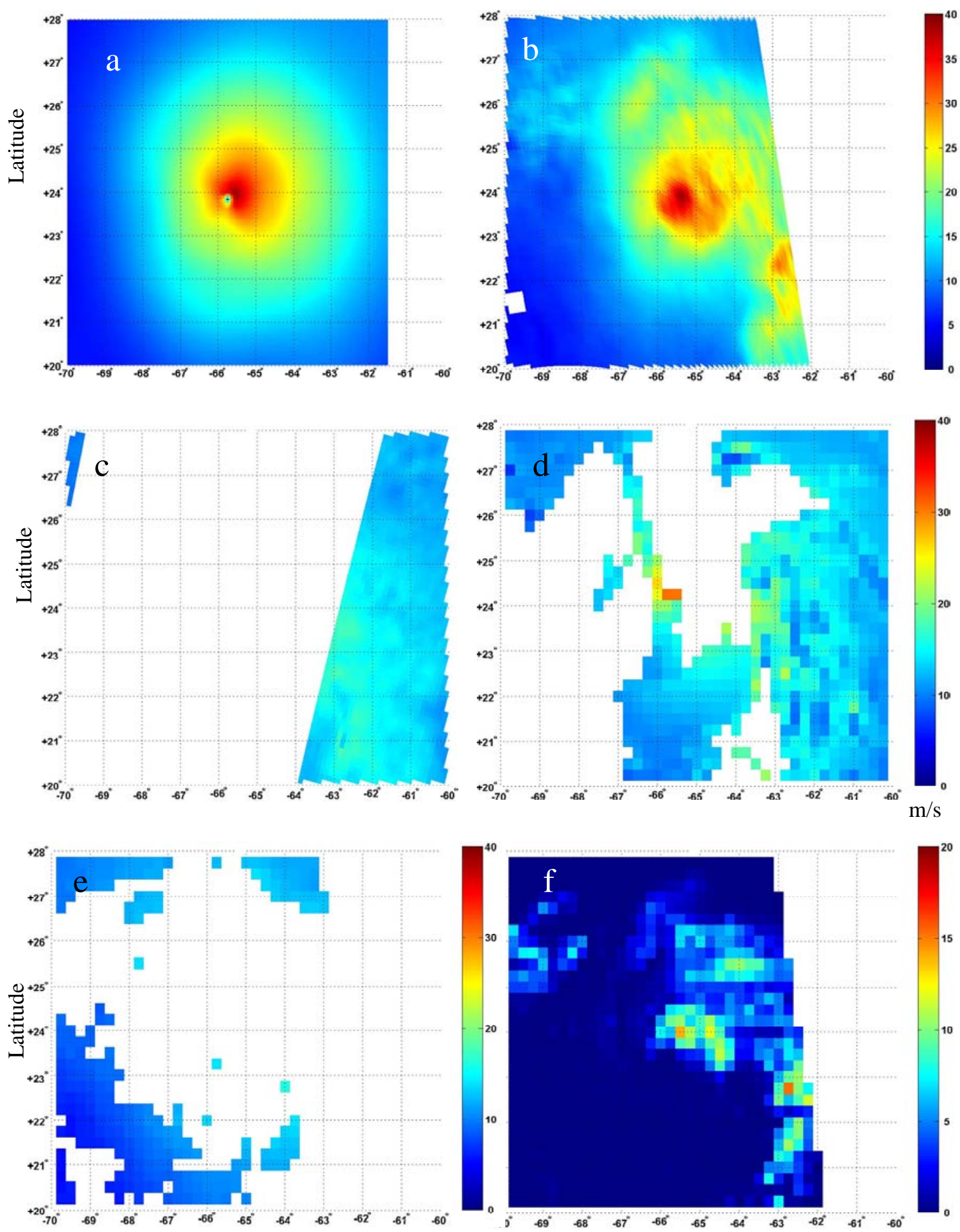

Longitude

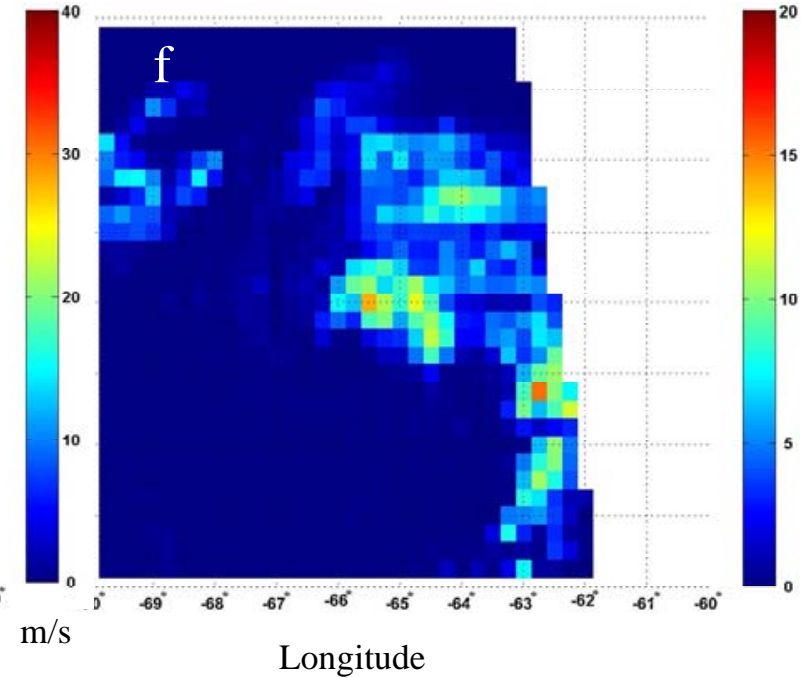

Zabolotskikh, Fig.9 

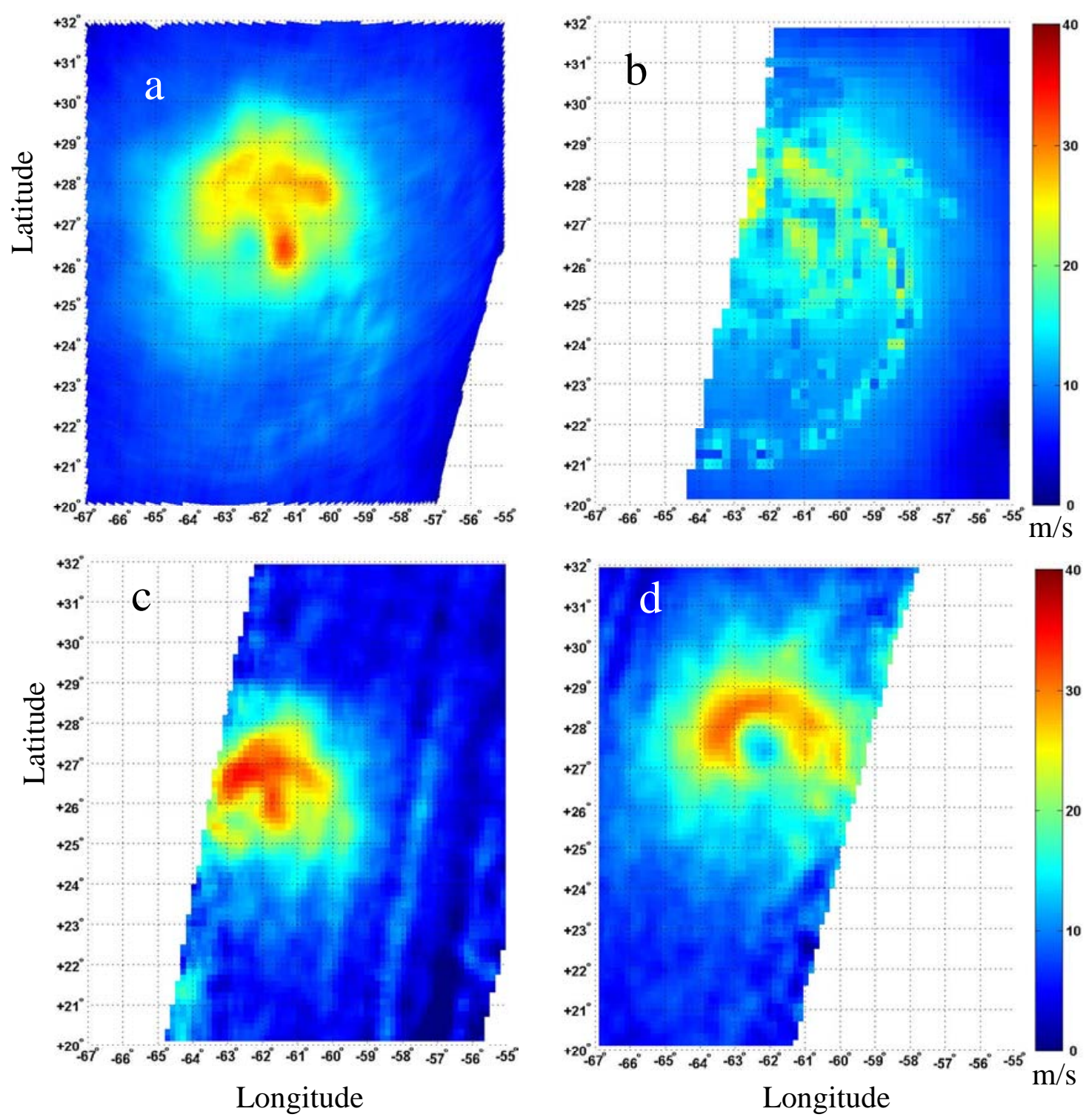

Zabolotskikh, Fig.10 


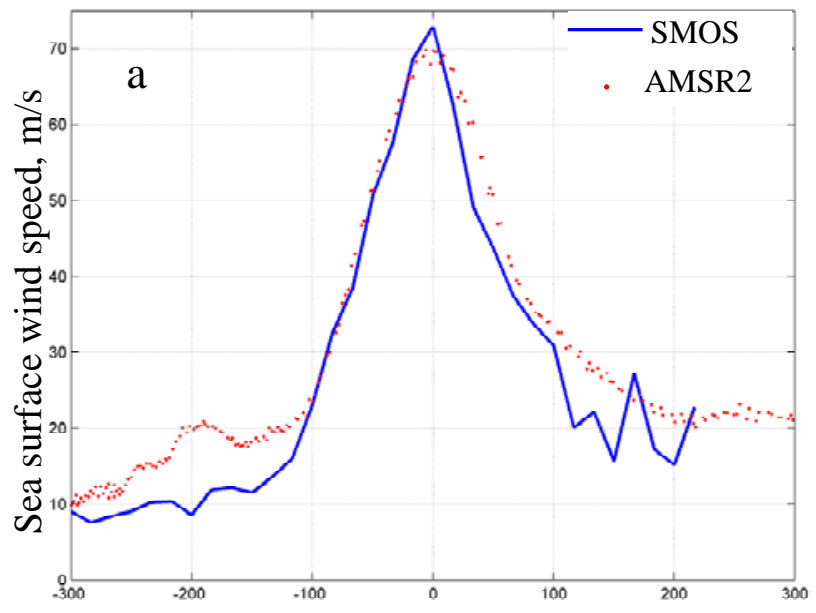

East-West section of the retrieved wind speed through the storm

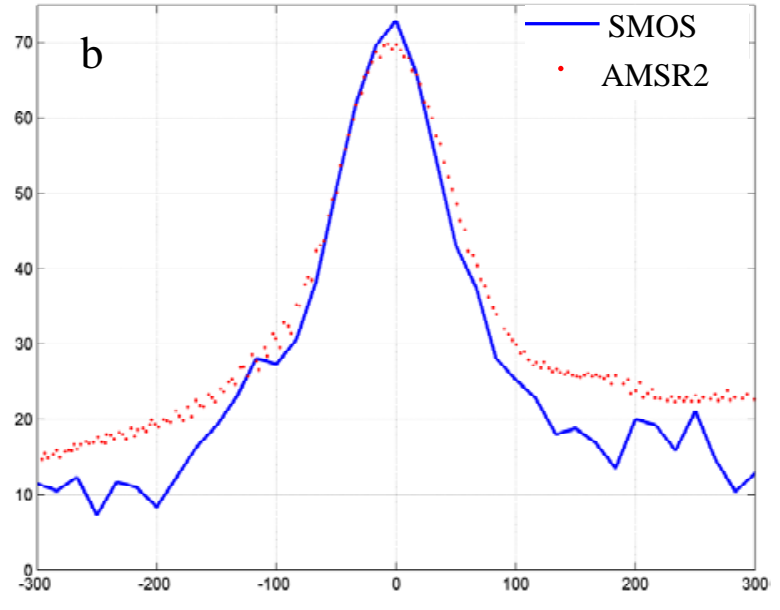

North-South section of the retrieved wind speed through the storm

Zabolotskikh, Fig.11 

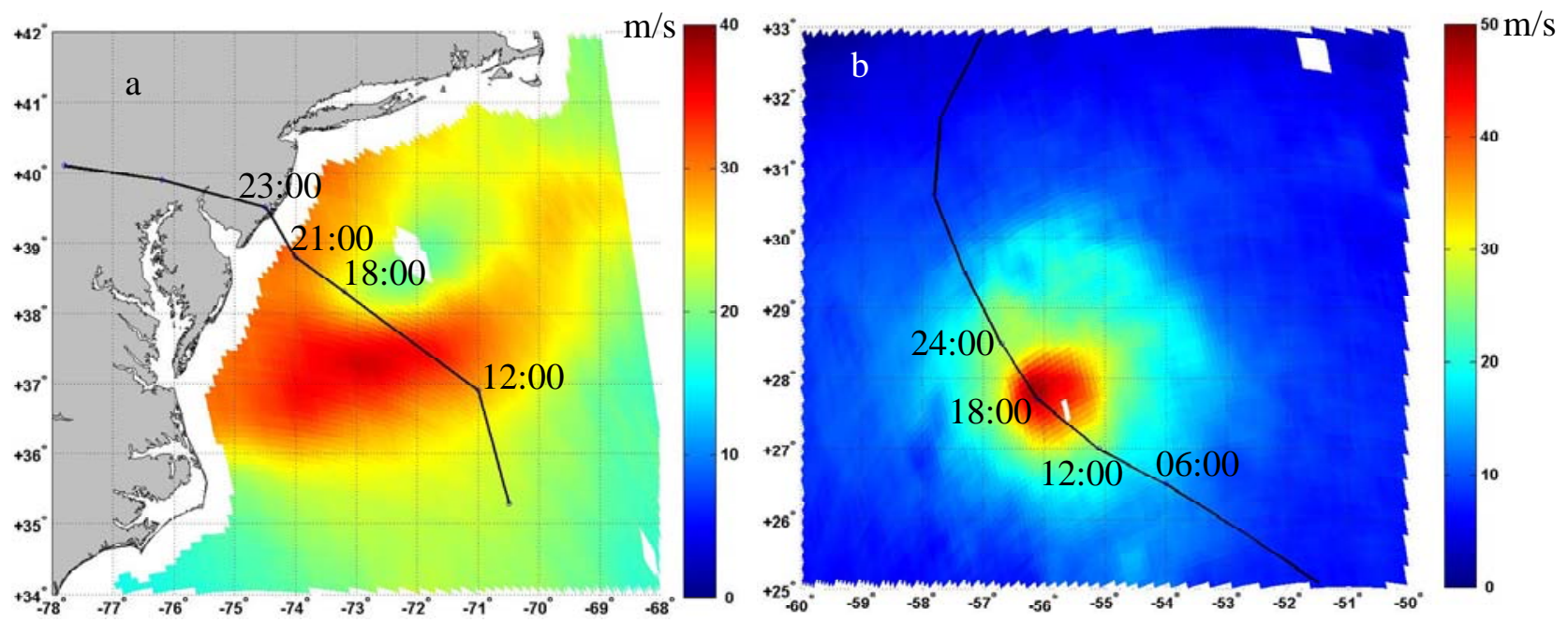

Zabolotskikh, Fig.12 

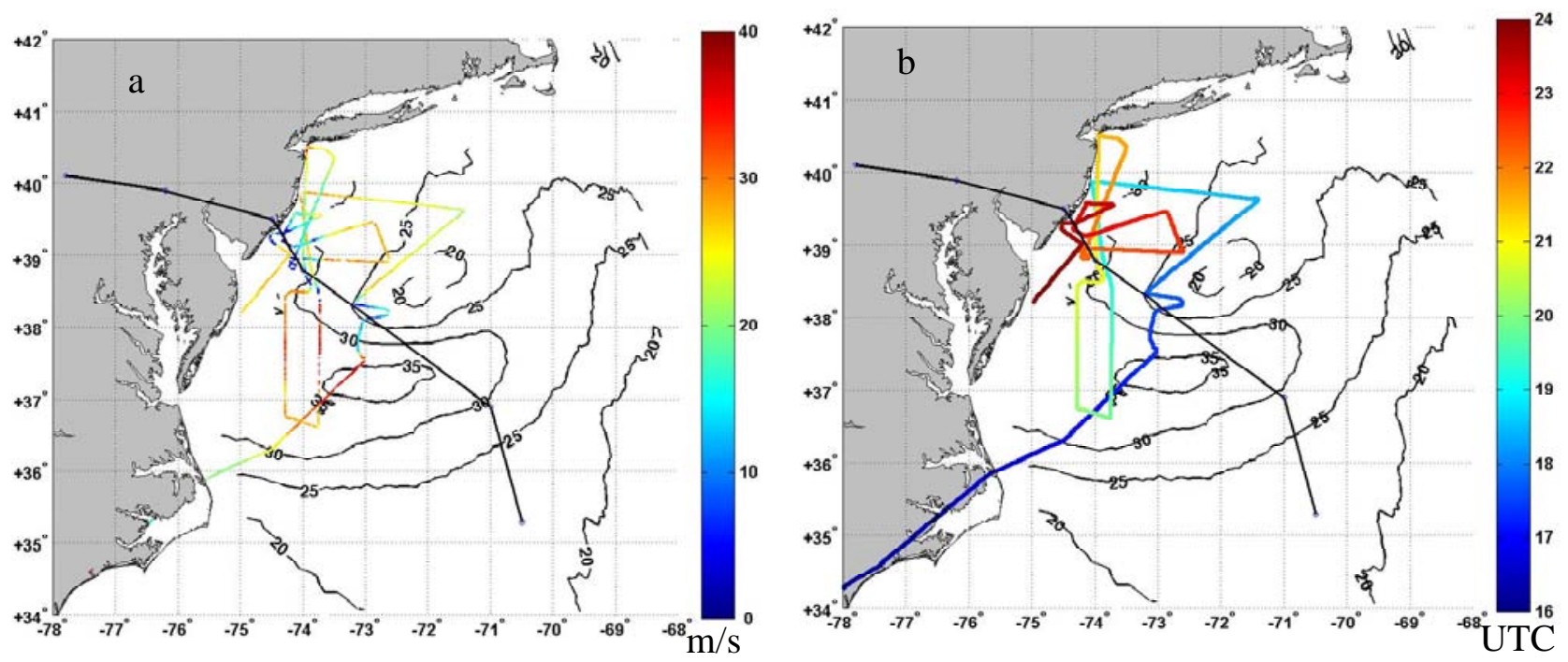

Zabolotskikh, Fig.13 


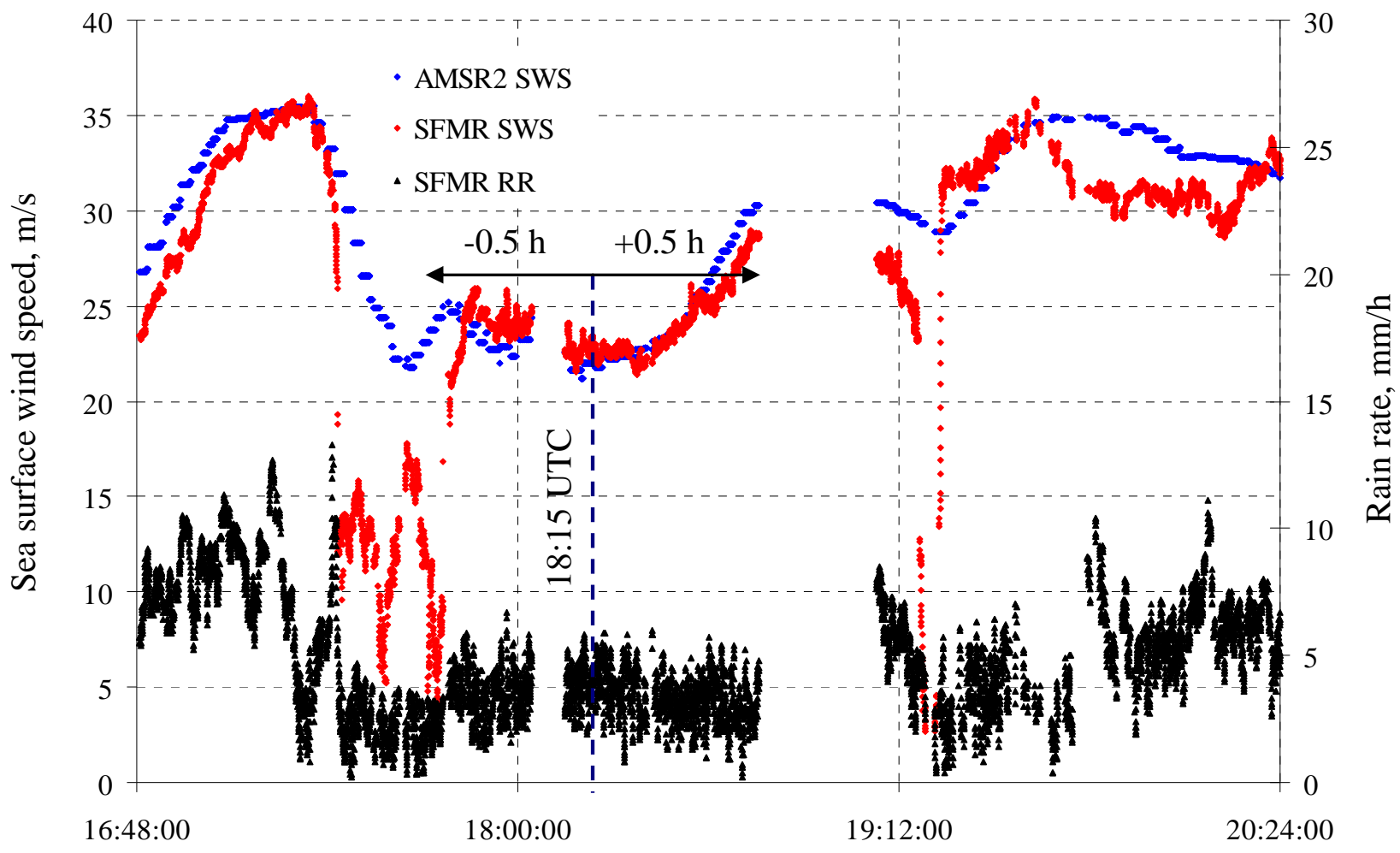

Zabolotskikh, Fig.14 


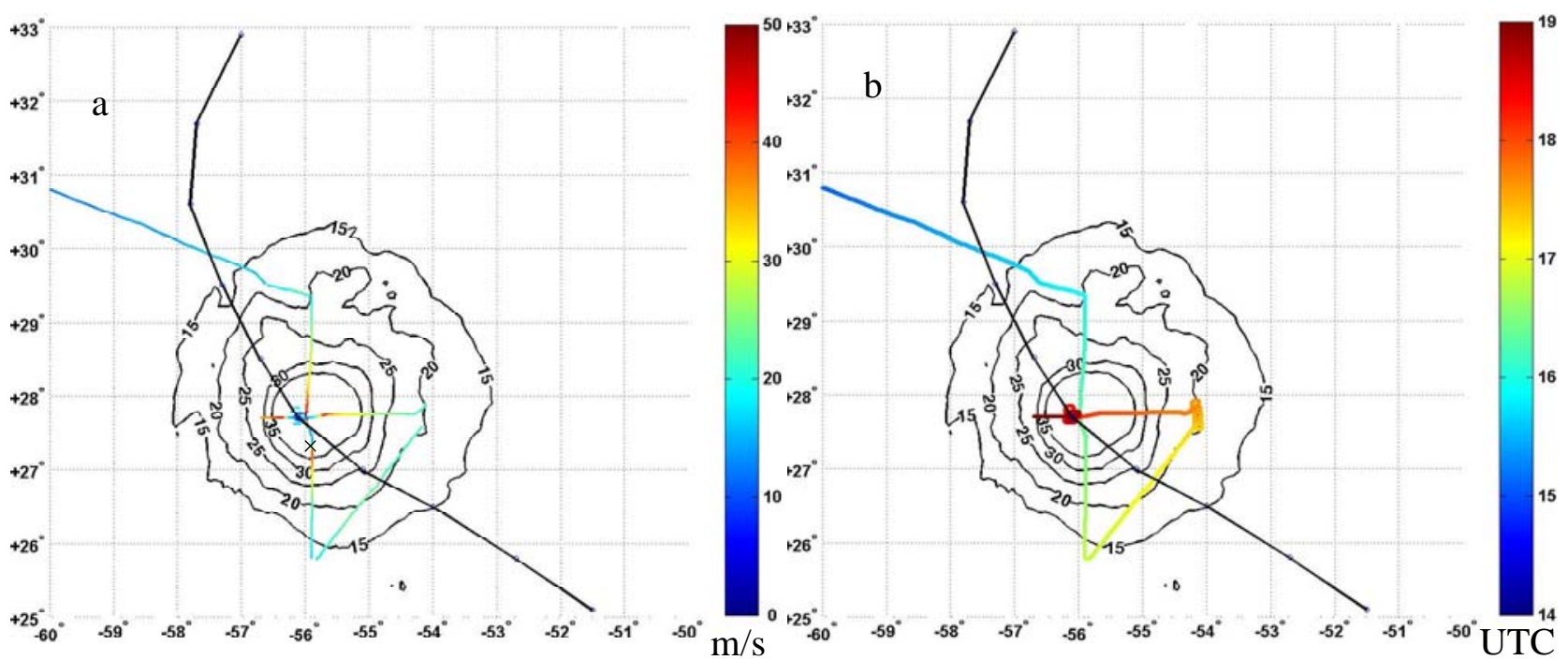

Zabolotskikh, Fig.15 


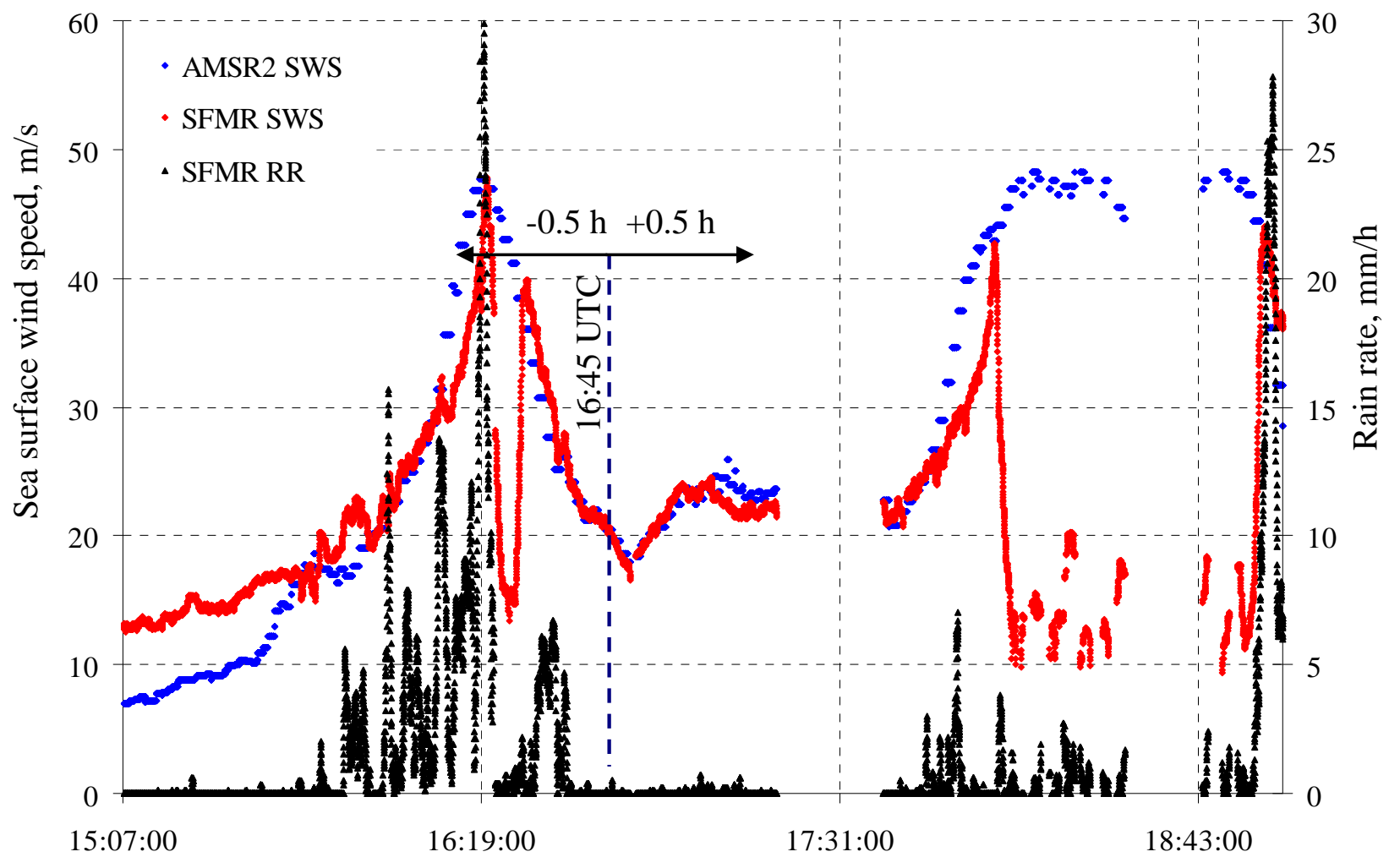

Zabolotskikh, Fig.16 